\title{
Aproximaciones a los imaginarios sociales del golpe de Estado en Honduras
}

FRANCESCA RANDAZZO

La tolerancia aparece como demanda política y virtud moral allí donde está amenazada la libertad o incluso la vida de las personas a propósito de sus creen-

cias o modos de vida;

o sea en el seno de una sociedad que no sólo las desprecia por diferentes, sino que las persigue por peligrosas. Aurelio Arteta, "La tolerancia como barbarie" (Cruz, 1998: 51)

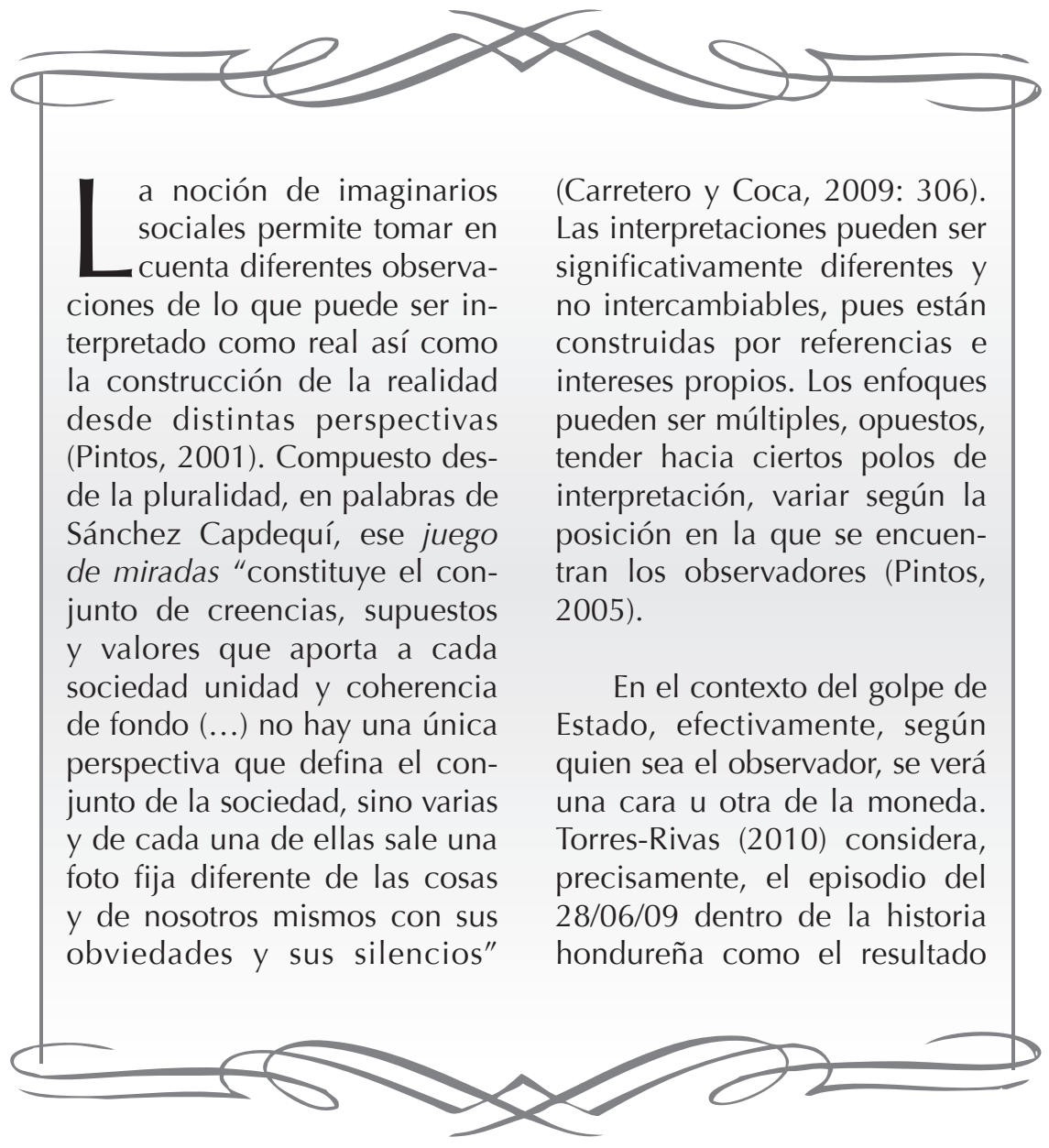


de "un profundo desencuentro de múltiples rostros". En función del lugar en el que se ubiquen los sujetos sociales el mismo acontecimiento será visto como un golpe de Estado o como una "destitución constitucional"; se considerará que lo que se establece es un gobierno de facto o un gobierno legítimo.
Finalmente, se conformará el movimiento de la Resistencia, el cual será negado por los medios y el grupo en el poder. Éstos, a su vez, serán llamados dentro del movimiento los "golpistas", materializándose así los polos de oposición que urdían antes del golpe.

\section{Imaginarios comunes, imaginarios diversos}

\section{a. Las raíces profundas de la polarización}

Desde el siglo XIX, en Honduras se mantenía un bipartidismo oligárquico de indefinidas fronteras programáticas, consolidado a partir del retorno a la democracia en los ochentas y carente de confrontaciones a pesar de las rivalidades (Torres-Rivas, 2010). Para Irías, Saravia y Sosa (2010) después del conflicto político-militar centroamericanos de los años 70 y 80 , Honduras ingresa en una fase signada por la implementación del modelo neoliberal, cuyos resultados son cuestionables, "para el caso centroamericano, la reforma fiscal neoliberal acarreó en la mayoría de países un sistema de exoneraciones para atraer ciertas inversiones (maquila textil principalmente), que pese a que contribuyeron a generar varios miles de empleos (muchas veces en condiciones laborales de explotación), también dejaron al Estado al margen de obtener ingresos fiscales directos por el enriquecimiento que esas empresas obtienen en nuestro suelo, y con nuestra mano de obra barata" (Cálix, 2010: 23).

En los escritos que circulan un mes antes del golpe en RDS, se afirma que "el denominado régimen democrático iniciado en 1980 no ha producido un tan solo gobierno de interés nacional y compromiso con sus gobernados los que, por lo contrario, únicamente han sido utilizados para consolidar un sistema de continuismo institucional que hasta hoy no ha hecho más que generar dependencia, pobreza, exclusión y miseria". ${ }^{1}$

Es decir que se responsabiliza al gobierno -liberal o nacionalista (los dos partidos mayoritarios)- de los problemas sociales, asegurando que han hecho de "...la democracia un modus vivendi, una mina de fácil explotación y de cuyas ganancias no hay que dar cuentas: les ha bastado con montar escenarios y falsas escenografías de instituciones movidas por hilos invisibles a su antojo".2 
Desde la visión expresada en RDS, los partidos tradicionales y sus gobiernos han conformado "un sistema de injustica": “¿Por qué no comenzar por entender y admitir, que el país es producto de las políticas y acciones de los partidos tradicionales y de quienes los han subsidiado? ¿O es que acaso son los de izquierda, o las maras o los maestros, los campesino, obreros, o la clase media quienes han gobernado y administrado a Honduras durante toda su historia?" ${ }^{3}$

Entre los años noventas y dos mil Irías, Saravia y Sosa (2010) reconocen tres momentos. El primero, de una economía tradicional dominada por la producción para la exportación del banano y el café, a una economía más diversificada, siempre para la exportación, sustentada por la generación de trabajo en la maquila. El segundo, de una sociedad signada por poderosas organizaciones campesinas y vigorosas organizaciones sindicales que incidían en la agenda nacional, a una sociedad socialmente fragmentada y precarización del mundo del trabajo. El tercero, de una sociedad altamente militarizada a una democracia electoral hegemonizada por los dos centenarios partidos políticos tradicionales dirigidos por una elite política y económica. Los autores responsabilizan a este grupo de la situación política, social y económica del país, por encontrarse

opuesta a construir un Estado de derecho y socialmente responsable, en otras palabras, un Estado con independencia partidaria de los poderes del Estado, con pesos y contrapesos, con mecanismos de transparencia y control ciudadano, con descentralización democrática y mayor participación ciudadana directa, con formulación y ejecución de políticas públicas para la inclusión social y la reducción de la pobreza. En su lugar, se establecieron "reglas del juego" que siempre beneficiaron a los pequeños pero poderosos grupos económicos-políticos, convirtiéndose el Estado en el principal instrumento para promover sus intereses (Irías, Saravia y Sosa, 2010: 8).

Un mes antes del golpe, además de un clima específico de desazón política, se percibe en RDS todo un ambiente social de malestar. Si bien concurren voces que responsabilizan a Zelaya de la situación que se vive, se atribuyen sobre todo a las elites políticas y económicas -en general- los males que padece la sociedad: desnutrición, pobreza, emigración, violencia, crimen organizado, entre otros: 
En Honduras por generaciones se ha venido enraizando un sistema de injusticia económica y social que abrió las puertas de par en par para que la corrupción, tráfico de drogas, lavado de dinero y la delincuencia común y organizada se desparramara hacia todas las instancias económicas y sociales. No debería de sorprendernos entonces el surgimiento de las maras, el descontrolado tráfico de drogas, el elevado grado de inseguridad, el contubernio entre delincuentes y algunos (pocos o muchos?) comerciantes y algunos (pocos o muchos?) empleados públicos, y muchos policías y militares (activos o en retiro). Todo esto era predecible!.... Me parece ridículo, absurdo que ahora pretendan asustarse de la situación los dirigentes políticos y empresariales cuando muchos de ellos han estado propiciando la actual situación". ${ }^{4}$

Se considera que "los enemigos del cambio han sido los grupos de poder que se han beneficiado y enriquecido de los recursos y los beneficios del Estado y han usufructuado las instituciones a su conveniencia absoluta, manteniendo sus privilegios a la sombra de la Constitución y mediante un sistema político formalista, cerrado y excluyente" ${ }^{\prime \prime}$

Cálix (2010) considera que la erosión de la confianza en las instituciones políticas, en especial los partidos políticos y asambleas legislativas, es un síntoma de la crisis de las democracias representativas en Latinoamérica en general y en América Central en específico. El autor atribuye este hecho a la inca- pacidad del sistema político de corte tradicional de procesar y resolver las demandas de los sectores vulnerables y acentuar las desigualdades.

Previo al golpe, en efecto, se encuentra en plena efervescencia un profundo cuestionamiento tanto del modelo político democrático como del económico. Se considera que "lo que está sucediendo en Honduras" es fruto de ese "sistema" que subvierte toda lógica al "evitar la participación directa de la población en la toma de decisiones que afectan la vida política y económica de los hondureños" ${ }^{\prime \prime}$. Conjuntamente, se atribuye la situación social de crisis al modelo capitalista, incoherente con los principios de la justicia:

Ese capitalismo insaciable se alimenta mediante la lógica de acumulación del capital, la que al mismo tiempo, se sustenta por la libre competencia empresarial que ha sacado provecho de los avances científicos y tecnológicos 
incrementando la producción y creando nuevas necesidades y hábitos de consumo. En un sistema capitalista -como el imperante en nuestro país- la apropiación de la riqueza está garantizada, es un derecho protegido por la ley y por el Estado, en este sentido, aún sigue teniendo vigencia el viejo enunciado del materialismo histórico de que "el Estado y el derecho surgen con el fin de conciliar las contradicciones de clase, en favor de la clase dominante sobre la clase dominada". Esta lógica, vista a través del sentido común nos muestra que cuando uno se apropia, muchos son expropiados, en buen castellano: "Para que uno tenga mucho, muchos deben tener nada", por esa característica, el capitalismo es un sistema que es incoherente con los principios de la justicia. ${ }^{7}$

Durante el periodo 1990-2008 si bien la tasa de crecimiento promedio anual del PIB es del $4.08 \%$ (determinado por el alto aporte de las remesas externas al PIB, que en el 2005 llegaron a representar el $25 \%$ del total), el crecimiento del PIB per cápita promedio fue apenas del $1.80 \%$, inferior al crecimiento de la población $(2.4 \%)$. La población bajo la línea de la pobreza se mantuvo en el $60 \%$ y se produjo un incremento de la desigualdad de los ingresos. El índice de Gini pasó de 0.494 en 1991 a 0.561 en el 2007, uno de los más altos de América Latina (Irías, Saravia y Sosa, 2010: 8). Se considera que los niveles de justicia distributiva están en estrecha relación con los grados de desigualdad socialmente tolerada:

En sociedades con altos niveles de exclusión, digamos con coeficientes GINI iguales o superiores a 0.50, la polarización social, aunque no tenga expresión política, está activada desde el mismo momento en que un puñado de individuos, familias y grupos ostentan una riqueza y un nivel de consumo ofensivo para el resto de la población. (Cálix, 2010: 17-18)

Cálix (2010) considera que la expansión o contracción del pensamiento revolucionario es relativa al nivel de desigualdad, el nivel de conciencia de las personas y gru- pos sobre su condición y ubicación dentro de la sociedad y el nivel de organización social que altera la correlación de fuerzas del grupo dominante o hegemónico. 
...la sociedad injusta, la sociedad capitalista, egoísta, explotadora, excluyente y violenta, como la que protege a esos grupos todopoderosos que se mecen a la sombra de la actual Constitución no puede más que producir ciudadanos y ciudadanas pobres, miserables y cada vez más carentes de dignidad". ${ }^{8}$

John Levine y Marc Pavelchak, en su trabajo "Conformidad y obediencia", consideran la conformidad como actitud para resolver el conflicto, a fin de armonizar el comportamiento de un grupo (la presión de grupo se ejerce inclusive cuando el juicio es en toda evidencia incorrecto). Esto puede hacer pensar en la aceptación de la situación política económica mientras existía la sensación de pertenecer todos a la comunidad imaginada. En el momento en que esta comunidad es puesta en tela de juicio y la sociedad se percibe polarizada, la conformidad ya no tiene razón de ser.

\section{b. Un atisbo de cambio y el límite de la provocación}

Mientras en Honduras predomina la sensación de que las cosas se encuentran empantanadas en materia social, económica y políti$\mathrm{ca}$, en el contexto internacional la izquierda latinoamericana se halla en un momento de cambio social y promesas, proveyendo posibilidades de significación para conformar esquemas capaces de dar un nuevo sentido a lo real por venir, a lo real imaginable.

Los gobiernos de izquierda que han surgido en los últimos tiempos en nuestra América han sido producto del voto popular cansado y agobiado del mal manejo de los mal llamados partidos "democráticos" tradicionales. Los tiempos han cambiado y hasta en los Estados Unidos de Norteamérica los aires del cambio soplan a pesar del gran poder del status quo! TODO CAMBIA por las buenas o por las malas...9

La consulta despierta los ideales populares al constituir un Ilamado inmediato, tangible, personal a una forma directa de participación. La consulta encarna la posibilidad de alcanzar una democracia participativa e inicia a mover un imaginario social desde el cual esa idea no es descabellada, sino algo totalmente alcanzable. El hecho es que en ciertos países, como Ecuador y Bolivia, la redacción de una nueva Constitución con la participación de los distintos sectores de la sociedad ha sido una realidad, quedando enmarcado dentro del rango de lo que puede ser concretizado. 
El grupo Comuna releyó la historia boliviana, en especial a partir de la revolución de 1952, descifró su significado, hizo las periodizaciones posteriores de la historia del país, comprendió los ciclos que llevaron al agotamiento de la fase neoliberal, consiguió deshacer los equívocos de la izquierda tradicional en relación con los sujetos históricos y realizó el trabajo teórico indispensable para concertar el casamiento entre el liderazgo de Evo Morales y el resurgimiento del movimiento indígena como protagonista histórico esencial del actual período boliviano. Pudo así recomponer la articulación entre la práctica teórica y la política, y ayudar al nuevo movimiento popular a abrir los caminos de lucha por las reivindicaciones económicas y sociales en los planos étnico y político (Sader, 2009: 8).

Justamente, durante su mandato, Zelaya realiza declaraciones acerca de la necesidad de realizar cambios sociales con el apoyo de las organizaciones populares. Dentro de su partido, el liberal, se desplaza hacia el sector que representa los movimientos gremiales, especialmente los sindicales, asociados a las organizaciones populares, y el partido Unificación Democrática, identificado con la izquierda (Romero, 2009).

Empero, si bien en agosto de 2007, Zelaya invitó a Honduras a Hugo Chávez y Daniel Ortega, y cambió su retórica (Torres-Rivas, 2010), ni él ni su grupo -al menos en el momento de golpe-, tenía claramente desarrollada una ideología que les identificara a nivel político o social, aunque la facción que lleva al poder a Zelaya tiene una tradición cercana a la izquierda. Precisamente, esa izquierda tradicional hondureña es objeto de crítica al sumarse a la iniciativa de la consulta, pues se considera una "propuesta surgida desde arriba y no desde abajo", que "ha servido como escenario para hacer aparecer a viejos "izquierdistas" que en un pasado reciente se habían acomodado -olvidando sus ideales- a los partidos políticos más tradicionales, ahora aparecen abanderados nuevamente con un discurso "revolucionario" que parece ponerse de moda". ${ }^{10}$

Justamente, para Romero (2009) es Zelaya el que durante su mandato decide la agenda del gobierno y del país, llevando a los distintos sectores a su terreno y no al revés. Sin embargo, esto debe ser leído cuidadosamente, pues a medida que Zelaya se distancia del Congreso -centro simbólico de la representación del pueblo- y de los grupos que detentan el poder económico -centro simbólico del poder detrás del poder-, se acerca a las organizaciones populares. 
Mediante acciones específicas, de gran contenido utópico, hace creer y sentir que las reivindicaciones idealistas se pueden materializar.

En concreto, Zelaya prohíbe las operaciones mineras a cielo abierto; logra acuerdos con el movimiento ambientalista en temas forestales en detrimento de los intereses madereros; respalda la huelga de los fiscales del Ministerio Público para denunciar los actos de corrupción; da seguimiento a las Asambleas del Poder Ciudadano en municipios del interior del país; crea un canal de televisión estatal, un periódico y un acercamiento a medios de comunicación privados para generar un contraste informativo, rompiendo el control tradicional de la opinión pública; fortalece las relaciones entre el Estado y las organizaciones representantes de los grupos étnicos; somete a licitación pública la banda $\mathrm{C}$ de telefonía móvil; cambia la fórmula para calcular el precio de los combustibles, su forma de compra, almacenamiento, así como la generación de energía; amplía los beneficios de los maestros; ejecuta compras sin intermediarios de medicamentos y promueve la compra estatal de genéricos; realiza las compras de armamento para las Fuerzas Armadas sin pasar por intermediarios; entre otros (Romero, 2009).

En lugar de perpetuar tácitamente el modelo capitalista, tal como lo habían hecho sus prede- cesores, Zelaya opta por provocar a las élites (de las cuales él mismo proviene), flirteando supuestamente con el chavismo. Ciertamente, el acercamiento del gobierno de Zelaya a la Alianza Bolivariana para los Pueblos de Nuestra América $(\mathrm{ALBA}) 11$ "llevó a su límite la confrontación del presidente con los partidos, los poderes Legislativo y Judicial, la Fiscalía, la Procuraduría, la prensa, la Iglesia, los gremios patronales, el Ejército" (Torres-Rivas, 2010: 5). Pero si bien el vínculo con la ALBA, Venezuela y Cuba, provoca a las elites locales, son las siguientes acciones las que aumentan la intensidad del conflicto político: proponer en la ONU y OEA un trato más justo a los migrantes ilegales y el reintegro de Cuba a la OEA; aumentar en un $62 \%$ el salario mínimo, equiparándolo al costo de la canasta básica de alimentos; retrasar la transferencia de fondos al Congreso y sueldos a diputados; imponer una consulta popular sobre la instalación de una cuarta urna en las elecciones de noviembre de 2009 , iniciativa orientada a la creación de una nueva Constitución; entrar en conflicto con la cúpula de las Fuerzas Armadas pocos días antes del golpe de Estado (Romero, 2009).

Aunque todas las señales mostrasen que estaba yendo en contra de los intereses del grupo en el poder, Zelaya y los seguidores de la consulta vieron el proceso de convocar la Asamblea Constitu- 
yente como un objetivo por el cual luchar, que podía ser realidad. Los imaginarios sociales hacen posibles las representaciones, las envisten de sentido y son capaces de influir con mucha fuerza en las maneras de pensar $y$, sobre todo, de decidir y orientar las acciones sociales, como auténticas fuentes de inspiración.

\section{c. Asamblea Nacional y el imaginario del cambio}

En el intercambio que se entabla a través de RDS, surgen respuestas, críticas, propuestas, en la forma de preguntas esenciales: “¿Será posible generar cambios sociales sin la dinámica consciente de los sectores populares, del ciudadano común? ¿Cómo cambiar esa visión de percibir a la sociedad como un todo y no como élites políticas? ¿Cómo dimensionar a los pobres como sujetos de la acción política y no como objetos de la misma?"12

Se comienza a soñar con una nueva sociedad, a pensar en cómo destacaría su organización, su igualdad económica y social. Existe la esperanza de "...fortalecer el surgimiento de una sociedad mejor organizada, fuerte, dinámica donde no existan esos grandes extremos de pobreza y riqueza; donde la mayoría viva con cierto grado de satisfacción y bienestar"13. Inclusive se escriben y comparten versos, cuya forma de expresión es común en la sociedad hondureña y suele estar asociada con los ideales (Randazzo, 2006):

¿Qué es/lo que los pobres/ responden/ cuando se les/ pregunta/ qué es/ lo que representaría/ el mayor cambio en su vida?// -Organizaciones propias/ para poder/ negociar con el gobierno, / con los comerciantes/ y con las organizaciones/ no gubernamentales./ -Asistencia directa/ mediante programas/ impulsados/ por las comunidades, / para que puedan/ elegir su propio destino./ -Propiedad local de los fondos, / para que puedan/ poner freno a la corrupción./ -Quieren que las organizaciones/ no gubernamentales/ y los gobiernos/ les den cuenta de lo que hacen... ${ }^{14}$

"Buenos Gobiernos: Honrados, Transparentes y Eficientes"15 es lo que exige la gente:

En concreto en Honduras se necesita más que espectáculos, discursos, necesitamos acciones de verdad, que se administren los bienes públicos y recursos en beneficio del pueblo, que se busque la manera, que la niñez y juventud acceda a la educación, a la salud y el alimento; los adultos 
necesitamos empleos, respeto a nuestros derechos laborales, trabajo, ingresos que nos den para vivir dignamente. ${ }^{16}$

Aspectos que se han vuelto estructurales en las sociedades contemporáneas comienzan a ser vistos como elementos que pueden ser revertidos. Así se plantea

...que en el país, se establezca de una vez por todas un sistema de vida verdaderamente democrático, al servicio ya no sólo del $17 \%$ de los habitantes ricos de la nación y de las compañías transnacionales, sino básicamente al servicio de $83 \%$ de la población hasta hoy victimizada por las relaciones de injusticia y desigualdad que imperan en la nación. ${ }^{17}$

Casi como un rezo se alza el clamor por un nuevo sistema económico, un sistema político incluyente, con equidad de género, tolerante, pero sobre todo "con una Constitución y una Honduras en pleno dominio de su pueblo":

Que nuestro sistema político y social requiere transformaciones importantes que nos permitirán rescatar los sectores estratégicos de nuestra economía, modernizar y adecuar los servicios públicos y las empresas estatales en función del desarrollo del país. Un sistema económico en el cual el ser humano sea el fin y el eje principal de nuestro desarrollo con énfasis en un estado incluyente de los pueblos y culturas indígenas nacionales, en la equidad de género y el respeto de los derechos ciudadanos. Que disminuyan las asimetrías sociales, económicas y culturales. Que nos garantice el ejercicio de nuestras libertades políticas en multiplicidad de ideologías, creencias y fundamentos. Que se democratice a los medios de comunicación. Que garantice el usufructo de nuestros recursos naturales en función del beneficio colectivo y que sean permanentes los mecanismos de la Democracia Directa en beneficio de una patria para todos, con una constitución y una Honduras en pleno dominio de su pueblo. ${ }^{18}$

Nuevas y viejas formas de organización popular-como los círculos patrióticos- son propuestas para "fortalecer el poder popular y derrotar a los enemigos eternos del pueblo que hacen hasta lo 
imposible por estrangular nuestros sueños libertarios y las aspiraciones

legitimas de construir una Honduras nueva y mejor"19.

En nuestro barrio, colonia, aldea, caserío, colegio, universidad, trabajo etc. Reunámonos libre y espontáneamente en grupos de dos o más personas y promovamos asambleas populares donde se debata y se decida todas las formas de participación para entender, apoyar, concretar y defender el proyecto político de instalación de una asamblea nacional constituyente y la elaboración de una nueva constitución como el marco jurídico-político para la transformación integral del estado de Honduras, llámese a este proyecto: Cuarta Urna, socialismo del siglo XXI, refundación del estado, o segunda independencia etc. ${ }^{20}$

La gente percibe que se ha conformado una "ciudadanía hondureña que exige ser tomada en cuenta mediante procesos de consultas y formas de expresión democráticas". ${ }^{21}$ La organización lograda por "la ciudadanía" para llevar a cabo la encuesta genera un clima de confianza ${ }^{22}$ que no era la norma en un tejido social más bien desarticulado. De hecho, hay claros signos de participación no sólo en los polos urbanos sino también en el interior del país. ${ }^{23}$ La forma en que se anhela que se realicen los cambios en las instituciones del Estado son concretas:

Aspiramos a cambios sustanciales en cuanto a la forma de elección de los titulares y el funcionamiento de los órganos contralores del Estado como La Corte Suprema de Justicia, El Tribunal Superior de Cuentas, El Ministerio Público, El Comisionado Nacional de los Derechos Humanos, Contraloría de la República y El Tribunal Supremo Electoral, instituciones que son la columna vertebral del Estado de Derecho. ${ }^{24}$

De tal forma, el conflicto gira en torno a las malas formas de gobierno versus la participación como valor supremo, en donde sería necesaria la

... renovación de anquilosadas estructuras políticas que han mal gobernado por decenios y que hoy se apertrechan bajo la conducción de caudillos ocultos, que fomentan la opacidad y permiten continuar con la estrategia de saqueo de los recursos de Estado en contubernio con sectores po- 
derosos, que actuando como neo colonizadores pretenden evitar la participación directa de la población en la toma de decisiones que afectan la vida política y económica de los hondureños. ${ }^{25}$

Se considera que estos cambios deben de venir, más que de los políticos, del pueblo mismo, en especial del proyecto de la cuarta urna ${ }^{26}$ que reúne la voluntad de las mayorías: "... la propuesta del Presidente ya ha pasado a convertirse en una verdadera y genuina aspiración de miles de hondureños y hondureñas que quieren ser tomados en cuenta, que exigen que se les consulte y que quieren decidir en un sistema verdaderamente democrático las vías que conducen a un destino de desarrollo y equidad". ${ }^{27}$ De allí la necesidad de una nueva Asamblea Constituyente

conformada por las representaciones de todas las fuerzas concluyentes de la ciudadanía, sin distinciones clasistas, étnicas o de género. Esa probablemente es la razón por la que una interminable fila de políticos (...) "analiza" las implicaciones que la redacción de una nueva Constitución tendrá para sus intereses pero nunca para los intereses del pueblo que dicen representar y gobernar. ${ }^{28}$

En el contexto del golpe de Estado, el $50.0 \%$ de los y las hondureñas expresaban que "la democracia hondureña se encuentra en crisis" (Irías, Saravia y Sosa, 2010: 20). La desconfianza en los políticos es flagrante y apunta en perfeccionar el modelo democrático incluyendo la participación real de los ciudadanos: "Según el latino barómetro (...) apenas el $2 \%$ de la ciudadanía confía en los políticos", afirma uno de los emisores. Los re- portes anuales de Latinobarómetro señalaban el incremento sostenido de la frustración ciudadana con la democracia electoral y los partidos políticos, calificando la situación hondureña como una pre-crisis, anunciando la inevitable ruptura del sistema político frenada por la inexistencia de una fuerza política constituida en alternativa genuina al "orden establecido" (Irías, Saravia y Sosa, 2010: 8). 


\section{Cuadro No.1.}

\section{Argumentos sobre la consulta y la constitución en RDS}

\section{Actual Constitución}

La democracia modus vivendi, mina de fácil explotación y de cuyas ganancias no hay que dar cuentas ${ }^{29}$ que produce ciudadanos y ciudadanas pobres, miserables y carentes de dignidad. ${ }^{30}$ El régimen democrático iniciado en 1980, (liberales como nacionalistas) ${ }^{31}$ produce un sistema de continuismo institucional. $^{32}$

La sociedad capitalista es injusta, egoísta, explotadora, excluyente, violenta; engendra dependencia, pobreza, exclusión y miseria. ${ }^{37}$ Se trata de un sistema de injusticia económica y social, con corrupción, tráfico de drogas, lavado de dinero y delincuencia común y organizada. ${ }^{38}$

Grupos todopoderosos ${ }^{43}$ caudillos ocultos, sectores poderosos, neo colonizadores, saqueadores del Estado. ${ }^{44}$

\section{Horizonte que abre la "consulta"}

La participación directa $^{33}$ responde a la voluntad del pueblo: "quiero representarme, quiero que se me escuchen, quiero saber que hacen con mi país". ${ }^{34}$ Significa "renovación de anquilosadas estructuras políticas" ${ }^{\prime 35}$ y gobernabilidad con equidad. ${ }^{36}$

El capitalismo es un sistema que es incoherente con los principios de la justicia. ${ }^{39}$ Los hombres son justos hacen una sociedad más justa. ${ }^{40}$ La justicia social viene de manos de una democracia ${ }^{41}$ con equidad, tierra, seguridad, dignidad. ${ }^{42}$

Pueblo decide al final su camino y destino, ${ }^{45}$ organizaciones, negras, indígenas, federación de trabajadores, artistas e intelectuales, empleadas domesticas, taxistas, buseros, las vende yuca, juventud, todo el pueblo consciente y organizado dieron su unánime respaldo al presidente y dieron su repudio a la oligarquía criolla ${ }^{46}$ izquierda, maras, maestros, campesinos, obreros, clase media. ${ }^{47}$

Con la posibilidad de una nueva Asamblea Constituyente, hay una suerte de júbilo alimentado por lo que está ocurriendo: "...hoy se abre a una nueva esperanza, la participación, el poder de la ciudadanía, el ejercicio de la no violencia y de la opinión directa, que mañana espera alcanzar una nueva constitución basada en el diálogo, la concertación, la esperanza y la búsqueda del bienestar común con equidad...". ${ }^{48}$ Estas líneas no dejan de hacer pensar en los planteamientos de Ernst Bloch $^{49}$ en El principio de Esperanza: "Da gusto y alegría ser parte de estos equipos de no violencia y refundación de una Honduras en la que prevalezca la cultura de la paz". ${ }^{50}$ "Buscamos refundar una Honduras que nos dé dignidad y que se sienta digna con nosotros y nosotras"..$^{51}$

La gente ve la oportunidad de lograr una "renovación histórica con justicia y dignidad"52, saldar una deuda con el pasado, lo que Benjamin (1982) Ilama un secreto acuerdo entre generaciones, porque "hemos sido esperados": "Mañana, se inicia a escribir una nueva página de historia de Honduras. Si la derecha no fuera ciega, esta es su 


\section{Imaginarios sociales en conflicto}

Existen al menos dos grupos distintos que construyen y estructuran su entendimiento de la situación de forma distinta a través de unas herramientas conceptuales y gnoseológicas características. Lo mismo puede concluirse a través de los discursos generados en los medios escritos sobre el 28/06/09: cada grupo construye y estructura su entendimiento de la situación a través de unos imaginarios sociales que les son particulares (Randazzo, 2010). Impedir la consulta y mantener la Constitución vigente se impone con unas categorías de comprensión del fenómeno social provenientes de unos imaginarios también específicos que denotan que existe una fe compartida en la relación imaginaria y las condiciones de existencia reales:

La sociedad imaginaria no es siempre aquella que hace cambiar la sociedad, ella puede por el contrario conservarla y hacerla durar. Olvidarlo sería desconocer que existe también una voluntad y un voluntarismo de la conservación. Se tiene ya bastante visto por lo demás el papel funcional (o funcionalizado) de lo imaginario (Carretero, 2001: 204).

La realidad material está indisociablemente ligada a representaciones subjetivas que le otorgan significaciones configuradas por un determinado imaginario social. Para Pintos (2001) es en torno al orden social que se producen las múltiples luchas por definir precisamente la relación entre la realidad y lo que se sabe de ella. Por lo tanto, el imaginario se traduce en el establecimiento de diferencias reales o imaginarias, poniendo barreras que separan realidades e intentando desde una controlar, dominar y gobernar lo 'otro'. Aquello que un grupo considera como lo real y lo posible, desaparece del campo de visualización social de otro grupo.

Si se considera unos hechos -que son desde el momento de su percepción misma socialmente construidos- y su interpretación a partir de un "punto ciego" -entendido como un contexto social de significado-, así como un posicionamiento binario y contrapuesto -al que se llamará una lógica A y una lógica no-A de lo real- en función de unos esquemas de significado vigentes y latentes se puede construir el cuadro comparativo que se encuentra a continuación. 


\section{Cuadro No. 2.}

\section{Comparativo de dos interpretaciones distintas de un mismo hecho}

\begin{tabular}{l}
\multicolumn{1}{c}{ Acontecimiento } \\
\hline $\begin{array}{l}\text { Recolección de las } 400 \mathrm{mil} \\
\text { firmas } \\
\text { Intervención de Venezuela }\end{array}$ \\
Consulta \\
Futuras elecciones del 29 de \\
noviembre de 2009 \\
Reelección \\
técnicamente imposible \\
Asamblea Nacional Cons- \\
tituyente
\end{tabular}

Precedente de 1980. Vuelta al orden constitucional Cambio de gobiernos militares a gobiernos democráticos.

Tres décadas de democracia.

Viernes 26 de junio de 2009

La Embajada de los Estados Unidos se abstiene de participar en el golpe planeado para ese día.

28 de junio de 2009

Art. 102 de la Constitución hondureña: "Ningún hondureño podrá ser expatriado ni entregado a un Estado extranjero".

Zelaya aparece en el aeropuerto internacional de Costa Rica.

\section{Interpretación desde una lógica A del orden de lo "real" \\ Interpretación desde una lógica no-A del orden de lo "real"}

Funcionarios amenazados

Pérdida de control sobre el rubro. Peligroso giro hacia la izquierda.

Acercamiento a otro tipo de modelo.

Participación democrática

Ilegal para casi la totalidad de las instituciones hondureñas.

Un paso hacia la Asamblea Nacional Constituyente.

Reelección / Continuidad de Zelaya o su grupo

Comprometer al siguiente gobierno Justificación del golpe para cambiar la Constitución.

Incluir responsabilidad social, Un grupo desprestigiado libertad de prensa, participación dentro de las elites de pociudadana, consulta popular, etc. der promueve un cambio en una nueva Constitución.

Mayor participación y más directa.

Cambio de la democracia representativa a la democracia participativa.

Modelo Ecuador y Bolivia. que puede ir en contra de los intereses de éstas.

Cambio de la democracia representativa (ejercer el voto) a la dictadura tipo chavista.

Nuevas e inusuales constituciones en el cono sur.

Golpe post-puesto: secuestro y expulsión de Zelaya el 28/06/09.

Intervencionismo asumido. EEUU visto como el guardia del panóptico.

Día de la encuesta

Un grupo de encapuchados viola el domicilio presidencial, y destierra a Manuel Zelaya Rosales.

Golpe de Estado.

Sin apoyo EEUU o de forma velada.

Roberto Micheletti designado mandatario interino.

Lectura pública de una supuesta carta de renuncia de Zelaya, firmada el 26/06/09.

La Corte Suprema de Justicia declara que los sucesos del 28 de junio forman parte de una «sucesión constitucional». 


\begin{tabular}{|c|c|c|}
\hline Acontecimiento & $\begin{array}{l}\text { Interpretación desde una lógica A } \\
\text { del orden de lo "real" }\end{array}$ & $\begin{array}{c}\text { Interpretación desde una } \\
\text { lógica no-A del orden de } \\
\text { lo "real" }\end{array}$ \\
\hline Frente de Resistencia & \multirow{3}{*}{$\begin{array}{l}\text { A las pocas horas de anunciarse } \\
\text { en los medios internacionales la } \\
\text { "deposición" de Zelaya se crea un } \\
\text { Frente de Resistencia. }\end{array}$} & \multirow{6}{*}{$\begin{array}{l}\text { Intervención de la policía } \\
\text { y las Fuerzas Armadas. } \\
\text { Cortes de la electricidad, } \\
\text { telefonía e Internet del } \\
\text { país. Toque de queda. De- } \\
\text { tención de los embajadores } \\
\text { de Cuba, Nicaragua y } \\
\text { Venezuela y la canciller } \\
\text { hondureña Patricia Rodas. }\end{array}$} \\
\hline Bloque Popular & & \\
\hline Machas MAO & & \\
\hline Dirigentes populares & \multirow{4}{*}{$\begin{array}{l}\text { Manifestación masiva en calles y } \\
\text { espacios públicos en todo el terri- } \\
\text { torio nacional durante semanas y } \\
\text { meses, y ahora años. }\end{array}$} & \\
\hline Fuerzas vivas & & \\
\hline $\begin{array}{l}\text { Precedente histórico la } \\
\text { Huelga de } 69 \text { días de } 1954\end{array}$ & & \\
\hline en Honduras & & $\begin{array}{l}\text { El Congreso decreta estado } \\
\text { de sitio y suspende las ga- } \\
\text { rantías de los ciudadanos } \\
\text { contenidas en } 8 \text { artículos } \\
\text { de la Constitución. }\end{array}$ \\
\hline
\end{tabular}

Los focos o puntos ciegos (Pintos, 2005) se construyen a través de la diferencia, por ejemplo, el blanco y el negro. El orden simbólico se asienta en pares oposicionales del tipo 'presencia-ausencia', como en el caso del día y la noche, por ejemplo; ya que es -además- un orden discontinuo y fragmentado por las oposiciones: cada significante es lo que los otros no son. En términos neurales, las ciencias cognitivas afirman que somos biconceptuales, que los opuestos se encuentran insertos en nuestros cerebros. Los modelos que se contradicen no pueden ser aplicados a la misma situación, en el mismo momento por la misma persona, por ser mutuamente inhibitorios: cuando se activa uno se desactiva el otro (Lakoff y Rockridge Institute, s.f.: 20).

\section{a. Escisión y conformación de grupos que se oponen}

El tema de la "consulta" demarca esa vaga división en dos "bandos", dando una razón concreta para ponerse de un lado o del otro, estando a favor o en contra. La barrera dentro de la sociedad hondureña se va materializando con la recolección de 400 mil firmas para la realización de la "consulta", acción desprestigiada por sus detractores asegurando que las firmas son recogidas por extranjeros y funcionarios públicos amenazados. Sin embargo, ese gesto de pedir firmas a la población muestra a las grandes mayorías que

el pueblo está dispuesto a cimentar una democracia renovada y refundar una nación, teniendo como piedra angular la consulta permanente para forjar procesos legítimos de una democracia activa, participativa y un sistema democrático 
basado en la no violencia activa y que resuelva el bienestar de las grandes mayorías. ${ }^{54}$

A partir de entonces, no hay como un acto contra el pueblo: “... vuelta atrás, pues las masas no están dispuestas a renunciar a la oportunidad de alzar su voz, y cada medida para frenar la consulta es asumida ya no quiero que me representen quiero representarme, quiero que se me escuche, quiero saber qué hacen con mi país...". ${ }^{55}$

Tradicional democracia electoral, que aún pervive, manteniendo vigente algunas de sus características: un poder Ejecutivo "electo" que funciona, dialoga, pacta y se confronta con los sectores populares; un Congreso Nacional "electo" que legisla y emite políticas públicas; gobiernos locales "electos" que administran sus territorios y coordinan acciones con la ciudadanía. No obstante, parte de su institucionalidad está erosionada y con limitadas capacidades de cumplir, de manera especial, con los requerimientos universalmente aceptados en defensa y promoción de los derechos humanos y aplicación independiente de la justicia.

Se trata, entonces, de la crisis de un tipo de democracia, de la democracia electoral, que no fue capaz en más de treinta años de resolver los problemas fundamentales de la ciudadanía: empleo digno, vivienda decente, educación y salud de calidad, la integración social y el derecho a la dignidad humana" (Irías, Saravia y Sosa, 2010: 14).

Así, se afirmará que quien debe decidir es el pueblo, pues las "dirigencias de izquierda, derecha o centro, los intelectuales laicos y/o religiosos" están "sólo para orientar", pues el "pueblo decide al final su camino y destino" ${ }^{56}$ Los bandos parecieran ser por un lado el pueblo, cuyo significado está profundamente ligado a la forma de gobierno, por ser en principio la base del poder en una democracia, y por otro las instituciones -base del Estado moderno- controladas por los grupos de poder desde tiempos ancestrales. Estos actores se irán amalgamando para formar un polo gravitacional de oposición, dentro de una "compleja situación política de Honduras caracterizada por la polarización política y social" (Irías, Saravia y Sosa, 2010: 10).

La poderosa minoría que ha tenido el control del país, desde su independencia de España, es la misma que impidió la 
consolidación de la República Federal de Centro América ${ }^{57}$, la misma que asesinó a Morazán ${ }^{58}$, la que combatió contra Cabañas ${ }^{59}$, la que mantuvo al país sumergido en el caos de la guerra civil, la que se entronizó mediante la dictadura y lamió las botas de los militares golpistas y cooperó con los militares asesinos que encabezaba Álvarez Martínez ${ }^{60}$ y que permitió la utilización del territorio nacional para agredir a países hermanos convirtiéndonos, como nos calificó Gregorio Selser" en "republiqueta alquilada", la que quiso convertirnos en protectorado de Los Estados Unidos, la que ha querido darnos atol con el dedo con una democracia hecha a su medida, está ahora contra la pared. Más no derrotada. ${ }^{62}$

Por un lado están quienes detentan el poder político y económico y que pretende representar a un pueblo que se siente explotado, y que con la esperanza de tener voz se vuelve gallardo, y se constituye como camino alternativo que se opone a la inercia de lo tradicional. ${ }^{63}$

... se trata de reconocer que los hondureños y hondureñas tenemos dignidad, que tenemos capacidad de decidir nuestro futuro y que ya no se nos vea como seres que no podemos participar, decidir, el mundo ha cambiado, Honduras debe cambiar, pero hay grupos interesados en que eso no suceda porque les conviene para sus intereses. ${ }^{64}$

Antes del golpe, la dicotomía se da en términos del esquema conformado entre el gobierno (aquéllos que controlan el Estado) versus el pueblo (aquéllos que conforman la Nación). Después del golpe, la izquierda como nueva identidad en Honduras, y la afirmación de la ideología conservadora: "Por un lado, actores representativos de los intereses de las elites tradicionales $y$, por otro lado, de los movimientos sociales articulados en oposición al golpe de Estado" (Irías, Saravia y Sosa, 2010: 20).
Si se presta atención a las demarcaciones visibles de la conformación de dos grupos, se ve, por un lado, que lo institucional no se confronta a los ciudadanos, su contraparte lógica, sino al pueblo. El pueblo es una denominación decimonónica dentro de una sociedad en la que se oponen las masas a la aristocracia en el contexto de la ilustración o de la revolución. Esto es importante a la hora de estudiar los "marcos". 
Ese pueblo que respalda la consulta y que cuestiona la forma de poder imperante tiene una visión incluyente, de facciones populares, recuperando las identidades excluidas, es aquél "representado por todas las organizaciones, negras, indígenas, federación de trabajadores, artistas e intelectuales, empleadas domesticas, taxistas, buseros, las vende yuca, juventud, todo el pueblo consciente y organizado dieron su unánime respaldo al presidente y dieron su repudio a la oligarquía criolla" ${ }^{65}$

El curso de los acontecimientos muestra cómo ante las alternativas (diálogo, consensos mínimos, búsqueda de mediadores...) lo que predomina es la confrontación ideológica que poco a poco irá reforzando las identidades mismas de cada grupo, así como sus objetivos. Grupo e ideología parecen definirse mutuamente, aunque no todos los grupos necesitan desarrollar una ideología. La lucha compartida por los recursos (incluso simbólicos) y la coordinación de acciones y realización de fines propician la generación de ideologías (van Dijk, 1998). Cuando los intereses sociales, económicos, políticos o culturales fundamentales de un grupo se confrontan a los de otro, el escenario es propicio para la conformación de ideologías. Los criterios de verdad se consideran ideológicos al entrar en conflicto con los intereses de otros y plantear problemas (reales o imaginarios) que conllevan una fuerte polarización entre Nosotros y Ellos (van Dijk, 1998).
A pesar de las opciones que se vislumbran al conflicto, la tensión entre los polos se mantiene. "Las posiciones de los dos polos siguen radicalizándose. Ni el Presidente parece dar un paso hacia un diálogo ni el otro sector está dispuesto a dar marcha atrás en su decisión de inhabilitar al titular del Ejecutivo". ${ }^{66}$ Cada nueva dificultad se convertirá en un aliciente más para dividir la sociedad hondureña. La confrontación y el antagonismo es visto como un momento necesario para alcanzar el cambio anhelado: "Debemos entender que es en ese ambiente de excesiva polarización entre los que mucho y nada tienen, que se han gestado desde siempre todas las revoluciones y los cambios sociales en el mundo" ${ }^{67} \mathrm{No}$ obstante, la violencia hasta el día de hoy sigue siendo el monopolio del Estado. El movimiento desde un inicio se mantiene al margen de las armas, y a partir del golpe, Zelaya en todo momento hace un Ilamado a la resistencia pacífica.

Inclusive se produce un razonamiento sobre la violencia como consecuencia de la oposición al cambio por parte de los grupos de poder: "En muchos de estos países el cambio no sólo ha sido difícil sino dramático y a veces también violento. Eso ha sido el resultado de una oposición cerril y terca de los grupos privilegiados que a toda costa están opuestos a los procesos de profundización, actualización y modernización de la democracia" ${ }^{68}$ 
Frente al deseo de las masas por tener una nueva democracia y una nueva constitución, se siente la oposición a los grupos de poder, dando pie para delinear de forma poco aduladora los rasgos del grupo de los otros: "No nos parece malo que en este debate (no muy definido como tal, por cierto) los que están en contra hayan decidido salir del clóset y cerrar fila para proteger sus intereses y privilegios de clase y para darse a conocer de manera meridiana en su pensamiento, ya sea éste honesto, conservador u oportunista." ${ }^{69}$ Hablar bien de Nosotros y "mal" de los Otros refuerza la polarización:

La autorrepresentación positiva y la representación negativa de los otros parece ser una propiedad fundamental de las ideologías. Asociadas con tales representaciones polarizadas sobre Nosotros y Ellos, están las representaciones de los acuerdos sociales, esto es, el tipo de cosas que encontramos mejor (igualdad, un ambiente limpio) o aquellas que creemos que los otros representan (la desigualdad, un ambiente contaminado, el libre mercado) (van Dijk, 1998: 95).

\section{b. Desobediencia}

La Fiscalía General, la Corte Suprema de Justicia y el Congreso de la República se unen a la opinión del Tribunal Electoral, declarando ilegal la consulta. El propio partido de Zelaya, el Partido Liberal de Honduras -que dicho sea de paso, es conservador-, manifiesta también su oposición a la controversial consulta. La propuesta de una consulta popular:

generó entre los opositores al presidente Zelaya la creencia de que se trataba de una argucia para continuar en el poder al vencerse su período, y que era además impulsada por los presidentes Chávez, Correa, Morales y Ortega para llevar a Honduras al comunismo, argumentando que en los países de dichos presidentes se habían tomado medidas similares con el mismo propósito. Las acciones del presidente Zelaya para disuadir estas creencias fueron casi inexistentes y los polarizantes discursos del señor Chávez llevaron a sus adversarios a reafirmar con mayor fuerza su creencia. El Congreso Nacional, los medios de comunicación, grupos de poder y sectores ciudadanos hicieron durante meses una fuerte oposición política, propagandística y judicial a la consulta sobre la cuarta urna. El presidente Zelaya desatendió acciones judiciales en su contra, encaminadas a demostrar la ilegalidad del procedimiento de la consulta y desacató ór- 
denes judiciales -de criticable legalidad- sobre este asunto. Con ello dio lugar a que se demandara en nuevas acciones judiciales que terminaron siendo usadas como pretexto para el golpe de Estado" (Romero, 2009: 30).

A pesar de la prohibición del Congreso, el presidente Zelaya continúa adelante con la promoción de la consulta y ordena que se distribuyan las encuestas. Las elites que controlan las instituciones del Estado hondureño lo más probable es que vean en Zelaya a un personaje peligroso y subversivo. Tal como el héroe trágico, Zelaya con sus acciones $-y$ posteriormente con sus regresos fallidos e inclusive con su ingreso clandestino del 21 de septiembre de 2009- busca el castigo, su propia destrucción, podría decirse que hasta la muerte ${ }^{70}$ con su comportamiento temerario.

El 27 de junio, el día anterior a la encuesta, el Congreso designa una comisión especial para investigar a Zelaya, "por desconocer los fallos de las instancias jurisdiccionales y violentar el Estado de Derecho". Solamente cuatro diputados del pequeño partido Unión Democrática -la izquierda en el país- se oponen a la moción de la Asamblea. Al enterarse que los principales grupos parlamentarios lo habían acusado de violar la Constitución y de estar incapacitado mentalmente, Zelaya responde: "Ustedes me han declarado la guerra, ahora aténganse a las consecuencias".

Cuando el jefe del Estado Mayor Conjunto hondureño, el general Romeo Vásquez Velásquez, se niega a acatar esa orden aduciendo una contraorden del Tribunal Supremo de Justicia, Zelaya anuncia su destitución en un mensaje televisado.

A mediados de junio, con casi toda la nación en contra, [Zelaya] ordenó a las Fuerzas Armadas que organizaran la distribución de la boleta electoral adicional [para realizar la "consulta"]; estas lo desobedecieron, por lo que el 27 de junio destituyó a su jefe, general Romeo Vásquez. En esa fecha, un tribunal judicial lo procesó, en tanto el Congreso decidió su destitución y ordenó su captura (Torres-Rivas, 2010: 5).

Con todas las instituciones en su contra, sólo el "pueblo" apoya a Zelaya:

La convocatoria a este proceso por el Ejecutivo contó con la activa oposición de los gremios empresariales, de la cúpula de las iglesias y de las corporaciones de los principales 
medios de comunicación. A finales de junio, el Ejecutivo quedo aislado del resto de los poderes del Estado y sin el respaldo de las Fuerzas Armadas y la Policía. Solo el histórico movimiento social mantuvo su apoyo al proyecto del presidente Zelaya de instalar la "cuarta urna" (Irías, Saravia y Sosa, 2010: 8-9).

Poco después de que el ministro de Defensa y los comandantes de las tres ramas de la Fuerzas Armadas hondureñas renuncian a sus cargos, el Presidente Zelaya irrumpe en una base de la Fuerza Aérea donde se guarda el material que el
General Vásquez se había negado a distribuir. Zelaya, junto a un grupo de ciudadanos, retiran el material de la consulta de aquel lugar. La recuperación del material que "custodian" los militares hace que la crisis política alcance su zenit:

Miles de personas rodean el palacio presidencial en Tegucigalpa apoyando al mandatario, confrontado por los sectores oligárquicos que se oponen a que se haga este domingo una consulta en torno a una Asamblea Constituyente. El Presidente y su pueblo realizarán una "misión" en defensa de la democracia, intentando recuperar el material electoral en posesión de los militares. En el fondo, se intenta evitar que se concrete un golpe de Estado en la nación centroamericana.

... Sus seguidores abordaron autobuses para realizar una misión "para garantizar los derechos de los hondureños", que en principio era secreta. Rafael Alegría, dirigente de Vía Campesina, confirmó a Telesur que la "misión" a la que se refiere Zelaya consiste en ir a la Fuerza Aérea, acompañados del pueblo que lo apoya, para intentar recuperar el material electoral que las fuerzas militares se negaron a distribuir, y que es necesario para realizar la consulta electoral este domingo. ${ }^{71}$ 


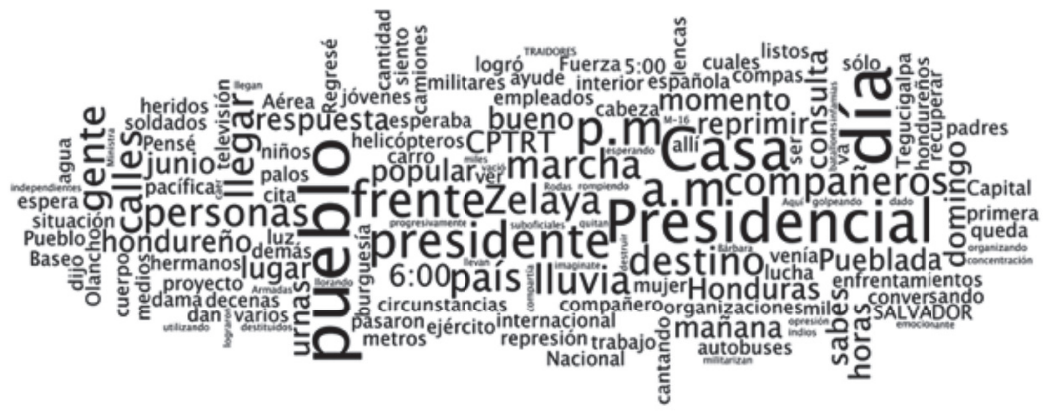

Nube de palabras No. 1. En el correo "En Honduras el Pueblo protagonizó una "Pueblada", del jueves 25 de junio, fui testigo", un extranjero, Erasmo Magoulas, describe los días anteriores al golpe, desde la perspectiva de quienes apoyan la realización de la consulta. Posteriormente sale del país y transcribe cómo un amigo desde Honduras narra el momento del golpe y los días posteriores, así como la conformación de un movimiento popular que se opone a lo que está ocurriendo.

Los sectores populares organizados, junto con el presidente, deciden seguir adelante con la consulta al margen de las instituciones del Estado, lo cual es paradoxal en el sentido de que se busca la democracia enfrentando las instituciones democráticas. Sin embargo, dentro del deseo de una mayor participación, "el rescate de las urnas" significa justamente actuar lo que se predica, aunque el procedimiento no se enmarque dentro de los lineamientos institucionalizados. Quizá justamente por eso, el gesto toma un cariz de heroísmo:

Rescataron las urnas de la consulta popular del domingo 28 de junio donde se hace una consulta popular para la creación de una Asamblea Nacional Constituyente que devuelve la Soberanía al pueblo Hondureño ansioso de cambios sustanciales en la democracia para el desarrollo de los sectores más pobres y lo cual tratan de impedir los oligarcas nacionales oscurantistas, amparados en la Corte Suprema de Justicia, el Tribunal Superior de Cuentas, el Ministerio Público, el Comisionado. ${ }^{72}$

Aparentemente, son las fuerzas armadas las que desobedecen a Zelaya, cuando es éste quien "rompe las reglas del juego", desafiando todas las normas de su mandato presidencial. Para C.P. Snow (1961) se han cometido más crímenes repugnantes en nombre de la obediencia que los que hayan podido jamás ser cometidos en nombre de la rebelión: 
When you think of the long and gloomy history of man, you will find more hideous crimes have been committed in the name of obedience than have ever been committed in the name of rebellion. If you doubt that, read William Shirer's "Rise and Fall of the Third Reich." The German Officer Corps were brought up in the most rigorous code of obedience... in the name of obedience they were party to, and assisted in, the most wicked large scale actions in the history of the world (Snow, 1961: 24).

De hecho, los estudios muestran que la desobediencia es posible sólo para una minoría, exigiendo la movilización de recursos internos, ejerciendo un coste psíquico considerable e implicando un sentimiento de traición. No obstante, una vez que la desobediencia "ha roto el hielo" toda tensión, ansiedad y temor desaparecen (Milgram, 1980: 143).

\section{c. Crisis, anomia y cambio}

En El avance de la insignificancia, Cornelius Castoriadis describe el imaginario social instituido -conformado por las significaciones imaginarias sociales y las instituciones cristalizadas- como aquello que asegura en la sociedad la repetición de las mismas formas que regulan la vida en sociedad, hasta que un cambio lento o una creación masiva las modifica o reemplaza. Catoriadis habla de las transformaciones que tienen lugar a través de la reorganización de lo significante.

¿Por qué Zelaya no logra negociar con los poderes vigentes, reorganizar las relaciones sociales, transformar paulatinamente las leyes? Quizá porque Zelaya es un personaje anómico, pero más que en el sentido de Durkheim, en el que desarrolla Duvignaud (1986). Frente a la actitud lógica común que define la vida colectiva y su conservación (cf. Durkheim y Merton), la anomia es lo contrario: es indiferente a la sobrevivencia del grupo e incita a la destrucción -la cual no es forzosamente violenta.

Cuando la coherencia social se debilita bajo el efecto de una crisis, se asiste a la aparición de algunos hechos incompatibles con los sistemas de control o de regulación admitidos y que se vuelven inexplicables, a-conceptuales. La anomia designa una serie de hechos o casos que no se reducen a ninguna regla que determine la normalidad o su contrario (Duvignaud, 1986). Por lo regular, la categoría de crisis se ha visto como interrupción de algo normal. Desde otra perspectiva (Tischler Visquerra, 2009), la crisis es la expresión del antagonismo de las relaciones sociales. La crisis es la antesala del cambio inminente. 
La situación social que orbita alrededor del golpe de Estado desborda las tentativas de reducción a visiones de mundo e ideologías: la anomía es un estallido dentro de la propia materia que lo contiene. Su núcleo duro es la subversión, justamente lo que hace Zelaya frente a cada oposición por parte de los poderes del Estado para detener la encuesta, y posteriormente frente a las Fuerzas Armadas.

Changer les normes établies par une culture ne consiste pas seulement à s'opposer à la vision officielle des choses, mais aussi à détruire son contraire -l'image que son répondant interne, son opposition, se fait d'une identique réalité. Car la subversion ne se place point là où se situe le contraire de l'ordre institué, mais là où n'existe plus aucun ordre ni aucune justification (Duvignaud, 1986: 29).

La forma de conducta de Zelaya es la subversión, y ésta destruye los contrarios. De hecho, la crisis política en Honduras va más allá de una lucha contra el capitalismo y por las izquierdas latinoamericanas. Su naturaleza es diferente al sistema en el que se encuentra y también a su antítesis. Porque la anomia es más que subversión, es una apertura de emociones inéditas, teniendo que ver con el aspecto anticipador de la utopía de Ernst Bloch.

Quelle est la transformation de l'expérience acquise qui ne doit pas à l'imaginaire son moteur premier? Quel changement humain n'a été formulé symboliquement à travers une fiction? Et quelle fiction ne s'est opposée, si elle est signifiante, à la culture où elle est apparue? Nous ne sommes pas faits de répétitions ni de formalisme, mais 'tissés de la matière de nos songes'... (Duvignaud, 1986: 31).

Poner en riesgo las relaciones sociales imperantes es profundamente desestabilizador, pero significa abrir posibilidades nuevas. Lo que marca Zelaya es la posibilidad de vivir, de sentir, de mostrar la afectividad de una manera inédita, fuera de lo "normal". De allí el apoyo, el cariño popular con que Zelaya no contaba previamente, pero que surge con una fuerza $y$ espontaneidad proporcional a la forma con que se reprime al pueblo y se le pretende encarrilar dentro del orden de lo "normal". En este sentido, se puede enmarcar también su Ilamado desde Costa Rica a la insurrección, a la desobediencia civil-comportamiento poco común por parte de un mandatario $-y$ la respuesta masiva e inmediata del pueblo. 


3. Caminos sin retorno. La consumación del golpe
de Estado y la irrupción de lo nuevo

El mismo 28/06/09, el Comité para la Defensa de los Derechos Humanos en Honduras comunica la creación de un frente cívico patriótico para repudiar al gobierno de facto. Esta agrupación pronto tomará el nombre de Resistencia y pos- teriormente se conformará como el Frente Nacional de Resistencia Popular, cuyas reivindicaciones serán afines a las de Zelaya, quien llegará a ser posteriormente el coordinador general del movimiento -desde el exilio primero y después a su regre- 
so a Honduras. Es posible encontrar una conexión de tiempos: el sujeto derrotado es parte del sujeto que avanza en tanto experiencia de lucha asimilada como conocimiento y memoria (Tischler Visquerra, 2009). El sujeto derrotado pasa a ser el sujeto en lucha.
El carácter temerario de Zelaya será la actitud adoptada por ese nuevo grupo y la consigna será resistir, desafiando mediante la presencia, la marcha, la unión. En efecto,

los protagonistas de la acción son individuos insertos en una situación de extremo peligro, pero están en ella no por la fuerza del destino, de ciegas circunstancias o de un capricho personal. Han elegido racionalmente el tipo de acción que están por ejecutar como parte de una estrategia revolucionaria. La acción, por otro lado, no es fría, como la de un militar de carrera. Implica el coraje fraguado en la lucha popular y en una vida cotidiana donde se respira la injusticia. Eso nos lleva al sentido de la acción en términos de praxis de un sujeto revolucionario (Tischler Visquerra, 2009: 86-87).

Se exigirá -hasta conseguirloel regreso de Zelaya y se insistirá en la conformación de una nueva Asamblea Nacional Constituyente. El derecho a la resistencia se encuentra incluido de forma explícita en la Declaración de los Derechos del Hombre y del Ciudadano de la Revolución francesa. Es un derecho reconocido a los pueblos frente a gobernantes de origen ilegítimo, que autoriza la desobediencia civil.

Se ha atribuido la convocatoria masiva que caracteriza el movimiento a las luchas populares y al trabajo de organización realizado durante los últimos años. "La memoria rebelde se nutre de los calendarios que marcan fisuras en el tiempo de la dominación, el cual no es un tiempo definitivamente cerrado, sino un tiempo que no ha llegado a ser" (Tischler, 2009: 33). Ciertamente, la firme y amplia red del sindicalismo ha sido uno de los cauces naturales del movimiento, así como las organizaciones campesinas, pero el sector informal y las maquilas conforman también un porcentaje de la población que encuentra en el grupo una forma organizada de lucha. Para Méndez (2010) el golpe de Estado, más que un Coup d'État es un Coup d'idées, pues al derrocar a Zelaya lo que se pretende es expulsar a un vector de ideas, y detener el surgimiento de un nuevo paradigma. Es decir, un cambio en la forma en que se dotará a la realidad de un nuevo sentido. 
Gráfico No. 1.

\section{Diferentes formas en que se relacionan los grupos en el contexto del} golpe de Estado.

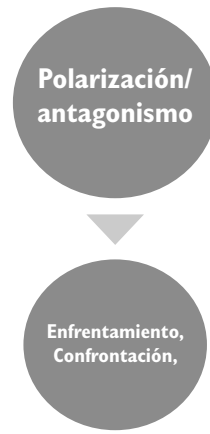

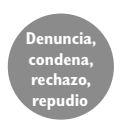
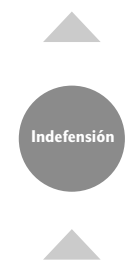

Represión,

persecución,

\section{b. La marcha como cambio y la represión como negación}

A partir del 28/06/09, la reacción masiva de manifestación del pueblo en las calles y espacios públicos en todo el territorio nacional durante semanas y meses tiene como único precedente histórico en Honduras la Huelga de 69 días de 1954. Considerar las manifestaciones permite pensar la lucha desde la lucha, "con las categorías que expresan el antagonismo, rompiendo con las formas culturales que son parte de la tradición de los vencedores" (Tischler Visquerra, 2009: 25).

Sin embargo, la reacción violenta y represiva por parte del gobierno de facto y la cantidad de asesinatos y violaciones a los derechos humanos en lo que va del mandato de Porfirio Lobo Sosa no tiene antecedente comparable, a pesar de que Honduras se encuentra entre los países más violentos y peligrosos de América Latina y su historia esté sembrada de masacres. La violencia institucionalizada se desata de una forma sin precedentes desde el mismo día del golpe de Estado, mientras se suceden las protestas, y Micheletti decreta el toque de queda por 48 horas con posibilidad de ampliación (lo cual se hará efectivamente de forma regular durante semanas y meses). Cortan la electricidad, telefonía e internet del país. La policía lanza gases lacrimógenos contra el pueblo en resistencia. Las Fuerzas Armadas hondureñas despliegan un dispositivo preventivo con varios aviones de combate y con 
soldados en las calles. Se prohíben las trasmisiones de cadenas internacionales dentro de Honduras. Detienen a varios periodistas. Se denuncia el secuestro de los embajadores de Cuba, Nicaragua y Venezuela y la canciller hondureña Patricia Rodas. En las semanas posteriores al 28 de junio, el Congreso decreta estado de sitio y suspende las garantías de los ciudadanos contenidas en 8 artículos de la constitución.

Pero así como el toque de queda "congela" el tiempo, así la oposición, la resistencia, la marcha, la movilización "llenan" el tiempo, resignifican los espacios de socialización, acción, construcción, creatividad, solidaridad, organización e intercambio: "Un tiempo que apunta a la redención del pasado oprimido en la temporalidad del dominio (...) caracterizado por un presente extendido horizontalmente como "tiempo Ileno" y superación del tiempo vertical del poder" (Tischler, 2009: 26). La violencia desatada no es capaz de detener el movimiento ni entonces, ni ahora.

Y hoy en día, se ha reactivado la protesta y la movilización para plantear demandas que el sistema político formal no quiere o no puede procesar, se ve como los dirigentes politicos oponen a los demandantes el brazo armado, bajo una racionalidad que criminaliza la protesta, antes que incorporar y empoderar a los actores excluidos que se sienten defraudados con las partidocracias. De modo que la lógica policial-militar se erige como el gran dispositivo estabilizador de sociedades desiguales, excluyentes y con vastos remanentes de una cultura autoritaria (Cálix, 2010: 30-31).

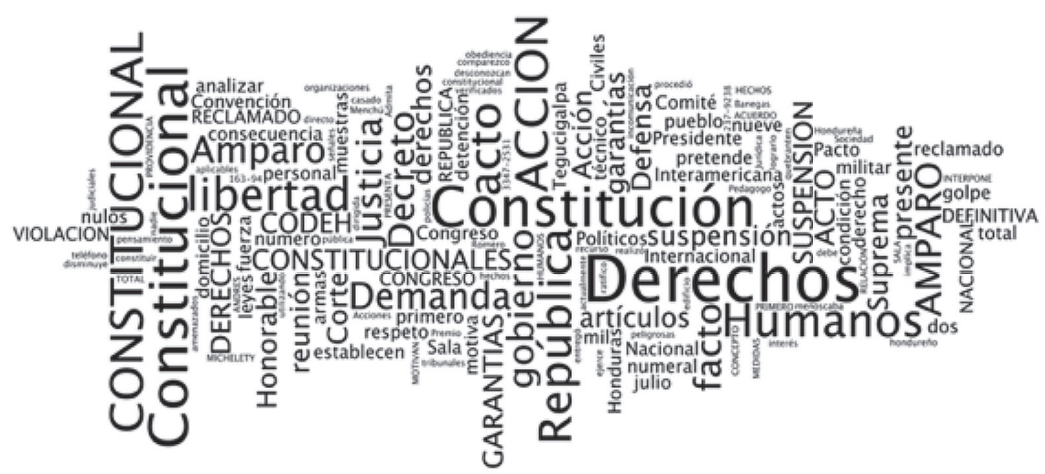

Nube de palabras No. 2. "Acciones judiciales presentadas ante los tribunales de Corte Suprema de Justicia Hondureña", del Bufete Romero Banegas y CODEH. Copia de la presentación de un Recurso de Amparo por violación de garantías y derechos humanos de la población, presentado por el CODEH, a través de su representante Andrés Pavón. 


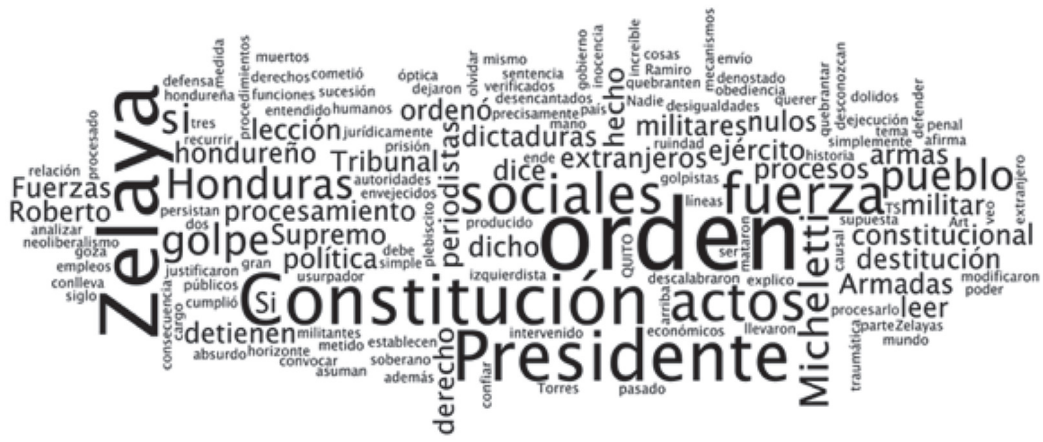

Nube de palabras No. 3. "Los procesos sociales no se detienen con actos de fuerza", de Ramiro Aguilar Torres. Desde Quito, Ecuador, el autor sostiene que se trata de un golpe de Estado y no de una sucesión constitucional. Procura una serie de detalles en tono objetivo, pero su posición es firme.

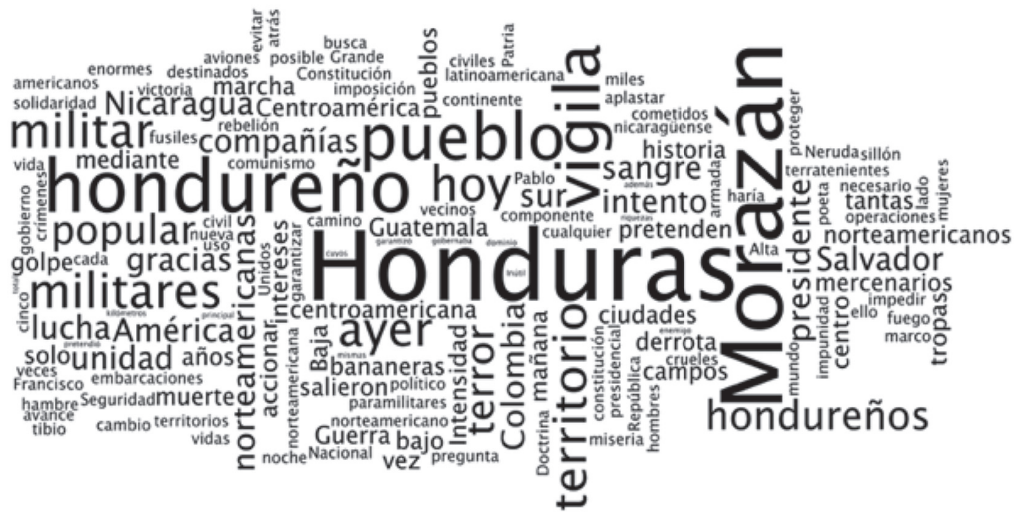

Nube de palabras No. 4. "02/07/09 y Morazán vigila", de Rosalba Moreno M. Texto lírico histórico lamentando la violencia social, política y económica del pasado y presente hondureño.

La marcha es la oportunidad de compartir "un tejido donde se entrelazan los hilos de las historias individuales, hecho de luchas cotidianas contra la explotación y la opresión, así como de eventos que condensan el descontento y adquieren formas conspicuas de manifestación colectiva" (Tischler, 2009: 41). Antes del golpe de Esta- do, la polarización desemboca en la conformación de unos grupos que encuentran a través de la movilización social los espacios de socialización que propician la búsqueda de símbolos de demarcación (vestirse de blanco o con la camiseta de la Selección Nacional de Fútbol ${ }^{73}$ ). Las identidades de grupo no se limitan a las representaciones mentales sino 
que incluyen prácticas típicas o rutinarias, acciones colectivas, vestimenta, objetos, lugares, monumentos, acontecimientos históricos, héroes, heroínas y otros símbolos; o en todo caso, la construcción cognitiva de éstos, es decir una compleja historia interpretada por la naturaleza simbólica del fenómeno (van Dijk, 2008).
Inclusive las fuerzas más conservadoras se inclinan a transformarse en movilización. Esta es convocada por colectivos hasta entonces desconocidos, como la Unión Cívica Democrática (UCD) o la Alianza para la Paz y Democracia:

I PLANTON del VIERNES 19 DE JUNIO no puedes faltar!/ Tenemos que apoyar a todas las personas e instituciones que nos han representado en este largo y precario camino./ Todos somos responsables del futuro de Honduras y de las generaciones por venir. Ven este VIERNES 19 de IUNIO a las 11 y 30 am al PARQUE CENTRAL, vestidos de blanco! LAMENTARSE DESPUES SERA MUY TARDE!/ Si no pueden ir, envíen a sus empleados, amigos, conocidos, nuestra meta son MILES de personas !!!!!/ Alianza para la Paz y Democracia. ${ }^{74}$

¿Quiénes están detrás de esa movilización? Algunos consideran que una "minoría, representada por el $97 \%$ de un Congreso Nacional corrupto, ha iniciado una guerra de gran intensidad que busca matar la iniciativa emprendida por el pueblo"75:

...un pequeño grupo de ciudadanos y ciudadanas que siempre se han auto determinado los más inteligentes, los más sabios, los poderosos, los que todo lo pueden hacer, aun violar cuando quieren la Constitución de la República y sus leyes, que pueden apropiarse de cuanto quieren, y cuando quieran, de poner y quitar gobernantes que respondan a sus propios intereses, que colocan, estructuran y nombran a sus peones donde más los necesitan, y es así, como ese pequeño grupo decide el presente y el futuro de este especial pueblo, manipulándolo, inundando al pueblo en su cerebro con novelas y películas violentas que solo perjuicios causan a sus propios valores éticos y morales, utilizando todos los medios a su alcance, que van desde medios escritos, radiales y televisuales y de todos los medios de comunicación, todo con la finalidad de que nuestro pue- 
blo no se dé cuenta de aquellas cosas que lo empobrecen, y estos pequeños grupos se enriquecen mucho más y más. ${ }^{76}$

Si bien ambos grupos recurren en un inicio a las manifestaciones, pronto será sólo "la marcha" de la resistencia la que adopte esta forma de expresión como la suya. En Honduras -como en muchos lugares existe- una tradición de marchar por causas que se podrían llamar "nobles". Marchas campesinas o ambientalistas han venido tomando lugar en los últimos tiempos en diferentes partes del país, en especial durante los últimos decenios. En el presente contexto político hay básicamente dos tipos de manifestaciones, caracterizadas de la siguiente manera:

- Marcha de la Resistencia. Se trata de recorrer varios kilómetros entre dos lugares significativos y/o plantarse frente a un lugar simbólico, como la Casa Presidencial o la estatua de Morazán (héroe centroamericano). La actitud de la gente que asiste puede hacer pensar en los estudios sobre el carnaval de Bajtin, por la actitud desafiante, buIlanguera, popular y hasta festiva. Aunque existe organización y disciplina, las masas encierran un elemento de osadía e irreverencia; también se caracteriza por ser su asistencia voluntaria. En el contexto de este tipo de manifestaciones, como puso de relieve Mijail Batjin al estudiar el carnaval, existe una transi- toria trasgresión y subversión del orden social instituido, de la sociedad institucionalizada, oficial (Batjin, 1971). La ruptura de las inhibiciones producida en la fiesta revivifica y refortalece el sentimiento de colectividad, que da la sensación de una refundición de la sociedad (Carretero, 2005). Se busca sobrepasar la realidad instituida, doble faceta de lo imaginario instituyente y el de lo imaginario instituido, la primera creadora de realidades, la segunda configuradora de lo comunitario. Se trata de una experiencia reencantadora del mundo, con un aura mítica, propiciando una participación afectiva (Sansot, 1986: 84).

- Marcha Blanca. Está impulsada -y aparentemente financiadapor las elites político-económicas. Si bien los hay quienes concurren por voluntad propia -empresarios y algunos altos funcionarios-, obligan a sus empleados a asistir (existen múltiples documentos que lo demuestran). También tienen un fuerte tinte religioso y las personas suelen escribir y pronunciar parte de sus lemas en inglés, rasgo común entre ciertas elites latinoamericanas para denotar su contacto con la cultura estadounidense y mostrar un mayor estatus. 
Las movilizaciones inician un mes antes del golpe, y son masivas después de éste, extendiéndose inclusive a diversas partes del mundo, gracias a diversas iniciativas que se solidarizan con la causa. La reacción y participación del pueblo en las calles y espacios públicos en todo el territorio nacional se extiende durante semanas, meses y ahora podemos decir años, en vista de que continúa en la actualidad. Denominada como "la marcha", esta actividad se ha convertido en la acción estrella por parte de la Resistencia.

Sin embargo, a diferencia de las ideologías, las identidades sociales no necesitan estar, como tales, limitadas al campo cognitivo. La identidad de grupo puede definirse, al menos parcialmente, en términos de las prácticas sociales características de los miembros de un grupo, incluyendo acciones colectivas. En efecto, los miembros de un movimiento social podrían identificarse tanto con las 'ideas' compartidas por el grupo como con actividades típicas de grupo como manifestaciones, huelgas, encuentros o rituales. Los rituales de iniciación pueden ser un criterio importante de pertenencia al grupo y por lo tanto de (sentimientos de) identificación. Lo mismo es cierto para los símbolos que identifican a un grupo, tales como uniformes, banderas, botones y muchos otros. Aquí también, teóricamente uno podría considerar tanto las prácticas sociales como los símbolos como expresiones o manifestaciones de una identidad de grupo 'subyacente' más abstracta, tal como hemos hecho con las ideologías (van Dijk, 1998: 158).

El día del golpe los sindicatos no tardan en reaccionar y anuncian una huelga general a partir del día siguiente. Los días posteriores tendrán lugar numerosas concentraciones y marchas organizadas, destacando la del 5 de julio, cuando entre 200,000 y 500,000 personas marchan hacía el Aeropuerto para la llegada -frustrada- de Zelaya. Mientras tanto, tiene también lugar otro tipo de manifestación, que destaca porque los participantes, entre los cuales se puede contar con la presencia de altas figuras tales como Roberto Micheletti y el jefe del Estado Mayor Conjunto, general Romeo Vásquez Velásquez, Ilevan "camisetas blancas".

A pesar de la criminalización de la protesta, la desinformación, la parcialización de la noticia, la violencia, el movimiento de la Resistencia no es detenido. Volcarse a las calles no era algo común en Honduras. Sin embargo, una semana después del 28/06/09, la 
manifestación, la concentración y "la marcha" son las formas de expresión de las masas. Comienzan a asistir cientos de miles de personas. Los líderes del bloque popular son asociados cada vez más con el movimiento de la Resistencia. La convocatoria masiva trasciende el movimiento de las luchas populares y su respectivo trabajo de organización y pasa de ser una fuerza política alternativa frente al "orden establecido".

El apoyo popular, la organización, la valentía de la gente, la firmeza de Zelaya, se implantarán implícitamente como razones para creer que la consulta $-y$ posteriormente la Resistencia- son posibles, definiendo al grupo y procurándole objetivos cada vez más claros de visualizar. El carácter temerario de Zelaya es la actitud adoptada por ese nuevo grupo, junto a la consigna de resistir, desafiando mediante la presencia, la marcha por las calles, la unión. La Resistencia se constituye reivindicando a Zelaya, quien será posteriormente el coordinador general del movimiento. El sujeto derrotado, pasa a ser el sujeto en lucha.

Los protagonistas de la acción son individuos insertos en una situación de extremo peligro que han elegido racionalmente actuar como parte de una estrategia que implica el coraje fraguado en la lucha popular y en una vida cotidiana donde se respira la injusticia (Tis- chler, 2009). Esto llena de sentido la acción de un sujeto cuya ausencia y capacidad de impugnar el "orden establecido" era recriminada.

Las marchas multitudinarias y frecuentes de la Resistencia son una experiencia reencantadora del mundo, que propicia la participación afectiva (Sansot, 1986). Así como el toque de queda "congela" el tiempo, así la marcha, la movilización supera "el tiempo vertical del poder" (Tischler, 2009: 26). La movilización social va estableciendo símbolos de demarcación, generando espacios de socialización y las identidades de grupo se refuerzan. Los espacios de socialización, acción, construcción, creatividad, solidaridad, organización e intercambio "Ilenan" de sentido la suspensión del orden de lo normal, resignifican la vivencia en común.

\section{Reflexiones finales}

El grupo que da el golpe no puede medir la reacción de la gente, las manifestaciones masivas, la conformación de una nueva fuerza política. Es como si no se pudiera entender más que al que piensa como el propio grupo, es decir, con el mismo marco. Si nuestra comprensión de lo que sucede no puede ir más allá de los modelos de explicación que son aceptados en nuestro grupo o en nuestra sociedad (Pintos, 2001a), ¿dónde queda en este razonamiento lugar para lo nuevo?, ¿cómo se enfrenta el tema 
de la dominación y de la reproducción de sus formas?

Ciertas cosas no pueden ser vistas si no existen ciertas capacidades para poder verlas. Se ha dicho también que son los que están fuera de una determinada realidad los que la cuestionan con más naturalidad, porque ven las cosas de otra manera, o porque ven otras cosas. Las personas con diferentes visiones de mundo piensan de forma distinta y pueden llegar a conclusiones diferentes a partir de los mismos hechos, aunque el racionalismo postule la razón universal. Es por eso que para encontrar los marcos o esquemas mentales es necesario repensar el racionalismo (Lakoff, 2007), pensar a "contrapelo" como diría Benjamin (2008).

El desafío de vivir en otro tipo de mundo -ese que la gente pareciera desear y relegar a la utopíano es imposible de realizar. Lo que es susceptible de acontecer tiene nexos con lo imaginable, lo pensable y la realidad misma; pero, ¿qué es lo posible o no de pensar-imaginar colectivamente? ¿Está escondida allí la idea del poder revolucionario de la esperanza?

Si bien los imaginarios sociales son configuradores y estructuradores de lo real, también es a través de ellos que se deslegitima y transforma la realidad social; es decir, que contienen los elementos que permiten la conservación pero también aquellos que propician el cambio y subversión del orden social. Los imaginarios vislumbran otros campos de lectura que marcan rutas alternativas de acceso a lo "real". Estamos hablando tanto de la facultad creadora, ensoñadora, utópica; como de lo que todavía-no es, de las deudas que reclama el pasado sobre el presente, de la capacidad de anticipar la experiencia actual sobre la experiencia que está por venir, de la posibilidad de recrear un mundo a la imagen de las esperanzas y los ideales en plena evolución.

Los imaginarios sociales potencian y limitan la elección de los códigos interpretativos, predeterminan lo que creemos que es posible de acontecer, pues contienen tanto lo potencial como lo coercitivo. Los problemas reales de una época o sociedad son aquellos que se encuentran acordes a su imaginario social. Los seres humanos no llegarán a resolver esos problemas sino en la medida en que son capaces de imaginarlos (Beriain, 2005).

Ciertamente, el golpe no es un hecho puntual sino el estallido de múltiples enfrentamientos entre el poder popular y el poder institucionalizado. A más de tres años del golpe, Honduras se encuentra todavía en plena efervescencia, y múltiples explosivos siguen aún detonando. El actual gobierno enfrenta un proceso de reconciliación nacional que no logra fraguarse, mientras la 
situación de los derechos humanos es cada vez más grave. Por lo tanto, la necesidad de ahondar en este tema no sólo no se agota en este modesto esfuerzo, sino que aviva el "aviso de incendio" vigente.

\section{Bibliografía}

\section{Libros y revistas}

- Aliaga Sáez, Felipe (2008) Imaginarios Sociales, Inmigración e Integración (TIT). Tutor: Juan Luis Pintos de Cea - Naharro. Universidad de Santiago de Compostela.

- Althusser, Louis (1965) Marxismo y humanismo. México: Siglo veintiuno editores.

- Benjamin, Walter (1982) "Tesis sobre filosofía de la historia", en Para una crítica de la violencia. México: Editorial Premiá.

- Beriain, Josetxo (2005) Modernidades en disputa. Barcelona: Anthropos editorial.

- Bloch, Ernst (2004) El principio de esperanza. Madrid: Editorial Trotta.

- Cálix, J. Álvaro (2010) Emancipación y cambio social: la acción colectiva de los movimientos sociales. Tegucigalpa: Satyagraha Editores.

- Campbell, Joseph (1984) El héroe de las mil caras. Psicoanálisis del mito. México: Fondo de Cultura Económica.

- Carretero Pasín, A. Enrique (2001) Imaginarios sociales y crítica ideológica. Una perspectiva para la comprensión de la legitimación del orden social. Tesis de doctoramiento. Universidad de Santiago de Compostela.

- Carretero Pasín, A. Enrique (2005) "La religiosidad futbolística desde el imaginario social. Un enfoque antropológico". A parte rei. Revista de filosofía. 41. Septiembre.

- Carretero Pasín, A. Enrique (2009) Pouvoir et imaginaires sociaux. La légitimation de l'ordre social dans les sociétés postmodernes. Paris: L'Harmatan.

- Carretero Pasín, A. Enrique y Coca, Juan (2009) Sociologías de los Márgenes. Libro homenaje a Juan Luis Pintos de Cea-Naharro. Huelva: Editorial Hergué.

- Castoriadis, Cornelius (1975) L'institution imaginaire de la société. Paris: Éditions du Seuil.

- Castoriadis, Cornelius (1992) Entrevista en video. Recuperado el 25/04/2011 en http://www.youtube.com/watch? $v=-$ CnuORRAdDE\&feature $=$ related 
- Coca, Juan (ed.) (2008) Las posibilidades de lo imaginario. Barcelona: Ediciones del Serbal.

- Coca, Juan (2010) Comprensión multifocal de los Imaginarios Sociales de la biotecnología. Tesis doctoral, Departamento de Sociología, Universidad de Santiago de Compostela.

- Coca, Juan; Valero, Jesús; Randazzo, Francesca; Pintos, Juan Luis (coord.) (2011) Nuevas posibilidades de los imaginarios sociales. Santa Uxía de Riveira: CEASGA.

- Conde, Fernando (2009) Análisis sociológico del sistema de discursos. Madrid: CIS. Cuadernos Metodológicos, 43.

- Cruz, Manuel, coord. (1998) Tolerancia o barbarie. Barcelona: Editorial Gedisa.

- Dittus Benavente, Rubén (2008) Cartografía de los Estudios Mediales en Chile. Concepción, Chile: Universidad Católica de la Santísima Concepción.

- Durand, Gilbert (2000) "Exploración de lo imaginal". Working with Images, Spring. Traducción de Enrique Eskenazi. Recuperado el 18/04/11 en

- http://homepage.mac.com/eeskenazi/durand2.html

- Durkheim, Emile (1968) Les règles de la méthode sociologique. Paris: PUF.

- Duvignaud, Jean (1986) Hérésie et subversión. Essais su l'anomie. Paris: Éditions la découverte.

- Duvignaud, Jean (1990) La genèse des passions dans la vie sociale. Paris: Presse Universitaire de France.

- Euraque, Darío (2010) El golpe de Estado del 28 de Junio de 2009, el Patrimonio Cultural y la Identidad Nacional de Honduras. San Pedro Sula: CENTRO EDITORIAL.

- Foucault, Michel (2004) Las palabras y las cosas. México: Siglo XXI.

- Geertz, Clifford (2000) Available Light. Anthropological Reflections on Philosophical Topics. New Jersey: Princeton University Press.

- Gómez, Pedro (2001) "Imaginarios sociales y análisis semiótico. Una aproximación a la construcción narrativa de la realidad". Cuadernos, febrero, No. 17, pp. 195-209.

- Heelan, Patrick A. (1982) "Hermeneutical Realism and Scientific Observation", PSA, Volume 1, Philosophy of Science Association, pp. 77-87. 
- Heelan, Patrick A. (1989) "Hermeneutical Phenomenology and the History of Science," in Nature and Scientific Method: William A.Wallace Festschrift. Ed. by Daniel Dahlstrom. Washington, D.C.: Catholic University of America Press, pp. 23-36.

- Heelan, Patrick A. (1991) Gadamer and Hermeneutics: Science, Culture, and Literature, Continental Philosophy. Continental Philosophy IV. Ed. by Hugh Silverman. New York: Routledge, pp. 213-228.

- Houtart, François (2010) "De la resistencia a la ofensiva en América Latina: cuales son los desafíos para el análisis social" en Cuadernos del Pensamiento Crítico Latinoamericano № 26. CLACSO, enero. Publicado en La Jornada de México, Página 12 de Argentina y Le Monde Diplomatique de Bolivia, Brasil, Colombia, Chile, España y Perú.

- Human Rights Council (2010) Report of the United Nations High Commissioner for Human Rights on the violations of human rights in Honduras since the coup d'état on 28 June 2009. Recuperado el 02/04/11 en

- http://www2.ohchr.org/english/bodies/hrcouncil/docs/13session/AHRC-13-66.pdf

- Ibañez, Tomás (2005) Contra la dominación. Barcelona. Editorial Gedisa.

- Ibarra, Pedro (1992) Ideología y nacionalismo. Vitoria: Instituto de Estudios sobre Nacionalismos Comparados.

- Inter-American Commission of Human Rights (2010) Report of the InterAmerican Human Rights Commission, 30th of December 2009. Recuperado el 02/04/11 en http://cidh.org/countryrep/Honduras09eng/Toc.htm

- Irías, Gustavo; Saravia, Francisco; Sosa, Eugenio (2010) Crisis política en Honduras. Escenarios posibles a diciembre de 2011. Informe de Análisis Político Prospectivo. Tegucigalpa: CESPAD-Oxfam.

- Lakoff, George (1987) Woman, Fire and Dangerous Things: What Cathegories Reveal about the Mind, University of Chicago Press.

- Lakoff, George (2007) No pienses en un elefante, lenguaje y debate político. Madrid: Editorial Complutense.

- Lakoff, George (2005) Framing -It's about Values and Ideas. Recuperado en http://georgelakoff.com/writings/rockridge/ el 22 de mayo de 2012.

- Lakoff, George y Johnson, Mark (1995) Metáforas de la vida cotidiana. Cátedra: Madrid.

- Lakoff, George y Rockridge Institute (s.f.) Thinking Points: Communicating Our American Values and Vision. http://www.cognitivepolicyworks. 
com/wordpress/wp-content/uploads/Thinking-Points-BETA1.pdf, recuperado el 21 de marzo de 2012.

- Ledrut, Raymond (1987) "Société réelle et société imaginaire", Cahiers Internationaux de Sociologie, 82, pp. 41-52.

- Lefebvre, Henri (1983) La presencia y la ausencia. Contribución a la teoría de las representaciones. México: Fondo de Cultura Económica. Recuperado en versión electrónica el 8 de mayo de 2012: http:// es.scribd.com/luisdo/d/16328900-Lefebvre-Henri-La-presencia-y-laausencia-Contribucion-a-la-teoria-de-las-representaciones-1980

- Liberman, Jean (1997) "Hablando con Cornelius Castoriadis. El avance de la insignificancia, Le Nouveau Politis 434, número 2, marzo.

- Luhman, Niklas (2001) "Poder, política y derecho", Sociedad y sistema (Pensar con y contra Luhmann). Metapolítica. Volumen 5/Núm.20, octubre/diciembre, pp. 11-39.

- Luhmann, Niklas y De Giorgi, Rafaele (1998) Teoría de la sociedad. Triana Editores.

- Méndez, María José (2010) The Honduran Coup d'ldées: US Aporia, Coloniality and Honduran Inurgency. Vassar College, Department of Political Science

- Milgram, S. (1980) Obediencia a la autoridad, Un punto de vista experimental. Bilbao: Editorial Desclee de Brouwer, 5ta edición.

- Misión de Verificación Internacional (2011) Honduras: Violaciones de Derechos Humanos en el Bajo Aguán. Informe Preliminar de la del 25 de marzo de. Recuperado el 01/04/2011 en http://www.resistenciahonduras.net/attachments/article/2478/Informe $\% 20$ Preliminar $\% 20$ Misi\%C3\%B3n\%20Internacional\%20entregado\%20a\%20la\%20CIDH. pdf

- Molinares Hassan, Viridiana (2005) "Los imaginarios sociales sobre el conflicto social y la forma como lo solucionan los pobladores del Barrio La Paz en Barranquilla (Colombia)", Revista de Derecho, Universidad del Norte, No 24, pp.106-139.

- Pintos, J. L. (1990) Las fronteras de los saberes, Akal, Madrid.

- Pintos, J. L. (1995a) Los imaginarios sociales. La nueva construcción de la realidad social, Instituto Fe y Secularidad/Sal Terrae, Bilbao.

- Pintos, J. L. (1995b) "Orden social e imaginarios sociales (Una propuesta de investigación)", Papers, 45: 101-127. 
- Pintos, J. L. (2001a) "Construyendo realidad(es): los Imaginarios Sociales", Realidad. Revista del Cono Sur de Psicología Social y Política, 1: 7-24.

- Pintos, J. L. (2001b) "Apuntes para un concepto operativo de Imaginarios Sociales", en Alburquerque, L. y Iglesia, R. (ed.), Sobre los imaginarios urbanos, Buenos Aires, FADU-UBA: 67-103.

- Pintos, Juan L. (2003) "El metacódigo relevancia/opacidad en la construcción sistémica de las realidades", RIPS (Revista de Investigaciones Políticas y Sociológicas), 2(1-2): 21-34.

- Pintos, Juan L. (2005a) "Comunicación, construcción de la realidad e imaginarios sociales", Utopía y Praxis Latinoamericana, 10(29): 37-65.

- Pintos, Juan L. (2005b) "Inclusión/Exclusión. Los imaginarios Sociales de un Proceso de construcción social", Revista Sémata, Facultad de Geografía e Historia. No. 16: 1-50.

- Pintos, Juan L. (2006a) "Imaginarios y medios de comunicación". En: Bouzada Fernández, X. (coord.) Cultura e novas tecnoloxías, Consello da Cultura Galega, Santiago de Compostela (España): 21-44.

- Pintos, Juan L. (2006b) "Comunicación, construcción de realidad e imaginarios", en VV.AA. Proyectar imaginarios, IECO-Universidad Nacional de Colombia-Sociedad Cultural La Balsa, Bogotá, Colombia: 23-66.

- Pintos, Juan Luis (2007a) "El valor epistemológico del demonio y el código de observación «Relevancia/Opacidad». Apuntes metodológicos", Anthropos, 215: 143-149.

- Pintos, Juan Luis (2007b) Algunos Imaginarios Sociales de la vejez. Versión electrónica recuperada el 11/12/10 en http://gceis.net/node/101

- Pintos, Juan Luis y Aliaga, Felipe (coords.) (2012) "Investigación social en torno a los imaginarios sociales". Revista de Investigaciones Políticas y Sociológicas (RIPS) VOLUME 11, núm. 2.

- Randazzo, Francesca (2010) Imaginario social y crisis política en Honduras. TIT. Universidad de Santiago de Compostela, Dto. de Ciencias Políticas.

- Randazzo, Francesca (2012) "Golpe de Estado en Honduras, colisión entre lo real y lo imaginario". Revista de Investigaciones Políticas y Sociológicas (RIPS) VOLUME 11, núm. 2, pp. 173-182.

- Reporteros Sin Fronteras (2010) Informe Mundial. Recuperado el 02/04/11 en http://es.rsf.org/report-honduras, 182.html 
- Revel, Jacques et Schmitt, Jean-Claude (1998) L'ogre historien. Autour de Jacques Le Goff. Paris: Gallimard.

- Ricoeur, Paul (1987) Tiempo y narración. Tomo I. Configuración del tiempo en el relato histórico. Madrid: Ediciones Cristiandad.

- Romero, Ramón (2009) Por la democracia y contra el golpe. Tegucigalpa: UNAH/ DVUS

- Rorty, Richard (1991) Contingencia, ironía y solidaridad. Barcelona: Editorial Paidós.

- Rorty, Richard (ed.) (1992) The Linguistic Turn: Essays in Philosophical Method. University of Chicago Press.

- Sánchez Capdequí, Celso (2003), "Apuntes para una biografía intelectual", Revista Anthropos, monográfico "Cornelius Castoriadis. La pluralidad de los imaginarios sociales de la modernidad", n 198.

- Sansot, Pierre (1986) Les formes sensibles de la vie sociale. París: P.U.F.

- Schutz, Alfred (1993) La construcción significativa del mundo social. Barcelona: Piados.

- Searle, John R. (2002) Conscious and Language. Cambridge University Press.

- Searle, John R. (2007) Freedom and Neurobiology. Columbia University Press.

- Steiner, George (2005) Gramáticas de la creación. Madrid: Ediciones Siruela.

- Tischler Visquerra, Sergio (2009) Imagen y dialéctica. Mario Payeras y los interiores de una constelación revolucionaria. Guatemala: F y G editores.

- Torres-Rivas, Edelberto (2010) "Las democracias malas en Centroamérica. Para entender lo de Honduras, una introducción a Centroamérica" en Cuadernos del Pensamiento Crítico Latinoamericano No 33. CLACSO, agosto de 2010. Publicado en La Jornada de México, Página 12 de Argentina y Le Monde Diplomatique de Bolivia, Brasil, Colombia, Chile, España y Perú. Recuperado online el 15/02/2011 en http://bibliotecavirtual.clacso.org.ar/ar/libros/secret/cuadernos/33/33.t.rivas.pdf

- Valencia G., Alberto (2003) Representaciones Sociales e ideología. Universidad del Valle, Facultad de Ciencias Sociales. Cali. Recuperado [online] el 13 febrero 2010 en 
http://socioeconomia.univalle.edu.co/pregrado/sociologia-paginaweb/ programas/programas-1 sem-2003/p-representaciones-prof-a-valencia1sem2003.pdf

- van Dijk, Teun A. (1998) Ideología. Una aproximación multidisciplinaria. Barcelona: Editorial Gedisa.

- Williams, Raymond (1976) Palabras clave. Un vocabulario de la cultura y la sociedad. Buenos Aires: Ediciones Nueva Visión.

- Williams, Raymond (1980) Marxismo y literatura. Barcelona: Ediciones península.

- Wittgenstein, Ludwig (2008) Investigaciones filosóficas. México: Crítica. 4ta edición.

\section{Corpus de textos electrónicos analizados}

\section{Hemeroteca Nacional de Honduras}

03-07-09 La Hemeroteca le Informa

02-07-09 La Hemeroteca le Informa

01-07-09 La Hemeroteca le Informa

27-06-09 La Hemeroteca le Informa

26-06-09 La Hemeroteca le Informa

25-06-09 La Hemeroteca le Informa

24-06-09 La Hemeroteca le Informa

23-06-09 La Hemeroteca le Informa

19-06-09 La Hemeroteca le Informa

18-06-09 La Hemeroteca le Informa

17-06-09 La Hemeroteca le Informa

16-06-09 La Hemeroteca le Informa

13-06-09 La Hemeroteca le Informa
12-06-09 La Hemeroteca le Informa 11-06-09 La Hemeroteca le Informa 10-06-09 La Hemeroteca le Informa 09-06-09 La Hemeroteca le Informa 08-06-09 La Hemeroteca le Informa 04-06-09 La Hemeroteca le Informa 03-06-09 La Hemeroteca le Informa 02-06-09 La Hemeroteca le Informa 01-06-09 La Hemeroteca le Informa 30-05-09 La Hemeroteca le Informa 29-05-09 La Hemeroteca informa 28-05-09 La Hemeroteca le informa 27-05-09 La Hemeroteca le informa 
Red de Desarrollo Sostenible

05-07-09 Más envíos sobre los sucesos del 5 de julio

05-07-09 Hoy una familia Ilora la muerte de un muchacho

05-07-09 Día 5 de julio termina la manifestación

05-07-09 Honduras 5 de julio 2009 sexto envío de mensajes

05-07-09 Séptimo día 5 de julio quinto envío

05-07-09 Honduras 5 de julio 2009 cuarto envío de mensajes

05-07-09 Séptimo día tercer envío de mensajes

05-07-09 Séptimo día 5 de julio segunda entrega

05-07-09 Séptimo día 5 de julio 2009

05-07-09 Séptimo día de resistencia Honduras

04-07-09 Teatreros salvadoreños en frontera hondureña

04-07-09 Boletín de empleos 4 de julio

04-07-09 Resistencia al Golpe de Estado
04-07-09 Antesala al eminente retorno de Zelaya

04-07-09 Expresiones particulares sobre el golpe

04-07-09 Expectativas del retorno de Zelaya

04-07-09 Secretario de OEA visita Honduras

04-07-09 Una Perspectiva diferente 04-07-09 Denuncian represión similar a los años ochenta

03-07-09 Organismo de Derechos Humanos

03-07-09 El hoy de la resistencia 03-07-09 El poder de la libertad

03-07-09 Denuncias de Represión 03-07-09 Libertad

03-07-09 Comunidad internacional continúa desaprobando golpe

02-07-09 Mensaje enviado 2de julio quinta parte

02-07-09 Mensajes 2 de julio segunda parte

02-07-09 Envío de mensajes 2 de julio 
01-07-09 Congreso suspende garantías constitucionales en Honduras

01-07-09 Resistencia Popular Continua

01-07-09 Segunda parte

01-07-09 Persistencia por la Democracia parte 2

01-07-09 Mensaje primero de julio

01-07-09 Defendamos la Constitución!!!!!!!!!!!!!!!!!!!!!!!!

01-07-09 12 mensajes del 20 de junio en este envío

30-06-09 Denuncia ante el Ministerio Público

30-06-09 Continúan las acciones de protesta

30-06-09 Marcha por la paz

30-06-09 Honduras en Rebeldía

30-06-09 Actividad Cultural Pospuesta

29-06-09 Persistencia por la Democracia

29-06-09 Secuestros de dirigentes de organizaciones sociales

28-06-09 Honduras 28 de junio $9 p$

28-06-09 Honduras 28 de junio $5 p$
28-06-09 Reportan muerte de líder popular al resistir al arrest

28-06-09 Urgente

27-06-09 RE Posición IV Urna, RDS

27-06-09 porque, RDS

27-06-09 HONDURAS ES PRIME$\mathrm{RO}, \mathrm{RDS}$

27-06-09 FW MEL Y SU GRUPO DE INMORALES Y CORRUPTOS, RDS

27-06-09 Con la vara que midas, serás

27-06-09 siete mensajes en este envío, RDS

26-06-09 SRC puros

26-06-09 invitación

26-06-09 Galería fotográfica a su disposición

26-06-09 seis mensajes en este envío, RDS

26-06-09 La hora de la razón, RDS

26-06-09 siete mensajes en este envío, RDS

25-06-09 La derecha quiere un 11 de abril

25-06-09 Dos mensajes en este envío 
25-06-09 Posición IV Urna

25-06-09 Documentos de Eduardo Barh

24-06-09 Comunicado COPA

24-06-09 V CONCIERTO DE TEMPORADA EN SPS

24-06-09 Boletín de empleos 24 de junio

23-06-09 CONCIERTO DE GALA Las Últimas Sinfonías

23-06-09 Presentación de libros Corral de locos

23-06-09 LA POSADA DE MIRANDOLINA de Goldoni

23-06-09 Presentación de libros Corral de locos

23-06-09 Cuatro mensajes en este envío

23-06-09 Exposición fotográfica de la Cruz Roja en la Alianza F

22-06-09 Invitación al estreno de nueva producción teatral

22-06-09 Este 23 y 25 de junio Café Paradiso

19-06-09 Únete al Plantan De Este Viernes

18-06-09 Paso la Bola, el gobierno de Mel y sus opositores
17-06-09 PROMOCION DE FERIA JUNIANA

17-06-09 Paso La Bola

17-06-09 Invitación al II Aniversario del Centro Documental

17-06-09 Muestra colectiva de fotografía Cuidad Imaginada

17-06-09 Boletín de empleos 17 de junio

16-06-09 Conferencia tema Encuesta de Opinión

16-06-09 TALLER DE TEATRO AEREO

16-06-09 Boletín de Clasificados 16 de junio

15-06-09 CAMBIO DE FECHA PARA EVENTO

15-06-09 Café Paradiso Visita Blog

15-06-09 Boletín de Becas y Cursos 15 de junio

12-06-09 Hoy 12 de junio Café Paradiso presenta lectura de

12-06-09 Anexo empleos 12 de junio

12-06-09 Gran Tele

12-06-09 sonando en Rock en Rebelión 
12-06-09 Sebastiana

12-06-09

11-06-09 El Inventario, blog contra el cinismo y la entrega, RD

11-06-09 DESDE LA MOVILIZACION DE LA IV URNA

11-06-09 Sito web Hondubirding and Nature Blog

10-06-09 Boletín de empleos 10 de junio

10-06-09 Casting para cine

10-06-09 Fiesta de la Música 2009

10-06-09 Noche beneficiosa Pro

10-06-09 EVENTO HISTORICO

10-06-09 Revista de críticas y respuestas, RDS

10-06-09 BALLET CLÁSICO DE MOSCÚ EN HONDURAS

08-06-09 Cine centroamericano Café Paradiso

08-06-09 Boletín de Becas y Cursos 8 de junio

08-06-09 Invitación de MUJERES SOCIALISTAS-LOLAS, RDS

05-06-09 Evento de HIP HOP
04-06-09 Vargas Llosa tiene un lucero en la frente y tinieblas

04-06-09 V Jornada de Bibliotecología en Honduras

04-06-09 ALBA Cultural, RDS

04-06-09 Presentación artística del CCAA

04-06-09 II Segunda Feria Ambiental

03-06-09 Boletín de empleos 3 de junio

29 26-06-09 seis mensajes en este envío, RDS.rtf - 45:5 [la democracia un modus vivendi..] $\quad$ (23:27).

30 25-06-09 Documentos de Eduardo Barh.rtf - 36:6 [saben que si los hombres son ju..] (32:32).

31 25-06-09 Documentos de Eduardo Barh.rtf - 36:18 [para nada reconocen que el den..] (55:55).

32 25-06-09 Documentos de Eduardo Barh.rtf - 36:18 [para nada reconocen que el den..] (55:55).

33 25-06-09 Posición IV Urna.rtf - 41:1 [La Red de Comisiones Ciudadana..] (11:24).

34 27-06-09 porque, RDS.rtf - 52:4 [no es el poder por el poder no..] $(6: 6)$. 
35 27-06-09 RE Posición IV Urna, RDS.rtf - 53:22 [La Red de Comisiones Ciudadana..] (75:75).

36 25-06-09 Posición IV Urna.rtf 41:3 [Nos ofrecemos a ser garantes d..] (44:47) y 27-06-09 RE Posición IV Urna, RDS.rtf - 53:26 [Nos ofrecemos a ser garantes d..] (75:75).

37 25-06-09 Documentos de Eduardo Barh.rtf - 36:18 [para nada reconocen que el den..] (55:55).

38 26-06-09 seis mensajes en este envío, RDS.rtf - 45:15 [borrando la página anterior do..].

39 27-06-09 Con la vara que midas, serás..., RDS.rtf - 48:2 [Ese capitalismo insaciable se ..] (7:7).

40 25-06-09 Documentos de Eduardo Barh.rtf - 36:6 [saben que si los hombres son ju..] (32:32).

41 26-06-09 siete mensajes en este envío, RDS.rtf - 46:3 [El Presidente, sin embargo nos..] (9:9).

\section{Notas}

1 25-06-09 Documentos de Eduardo Barh.rtf - 36:18 [para nada reconocen que el den..] (55:55).

2 26-06-09 Seis mensajes en este envío, RDS.rtf - 45:5 [la democracia un modus vivendi..] (23:27).

3 18-06-09 Paso la Bola, el gobierno de Mel y sus opositores.rtf - 29:4 [porque no comenzar por entender..] (80:85)
42 26-06-09 seis mensajes en este envío, RDS.rtf - 45:53 [los hondureños y hondureñas c..] (481:486)

43 25-06-09 Documentos de Eduardo Barh.rtf - 36:6 [saben que si los hombres son ju..] (32:32).

44 27-06-09 RE Posición IV Urna, RDS.rtf - 53:22 [La Red de Comisiones Ciudadana..] (75:75).

45 18-06-09 Paso la Bola, el gobierno de Mel y sus opositores.rtf - 29:7 [Cada pueblo decide al final su..] (128:135).

46 26-06-09 siete mensajes en este envío, RDS.rtf - 46:14 [El pueblo representado por tod..] $(27: 28)$.

47 18-06-09 Paso la Bola, el gobierno de Mel y sus opositores. rtf - 29:4 [porque no comenzar por entender..] (80:85)

4 26-06-09 seis mensajes en este envío, RDS.rtf - 45:15 [borrando la página anterior do..].

5 25-06-09 Documentos de Eduardo Barh.rtf - 36:39 [En todos esos países los enemi..] (93:93).

6 25-06-09 Posición IV Urna.rtf - 41:1 [La Red de Comisiones Ciudadana..] (11:24). 
7 27-06-09 Con la vara que midas, serás..., RDS.rtf - 48:2 [Ese capitalismo insaciable se ..] (7:7).

8 25-06-09 Documentos de Eduardo Barh.rtf - 36:6 [saben que si los hombres son ju..] (32:32).

9 18-06-09 Paso la Bola, el gobierno de Mel y sus opositores.rtf - 29:12 [Los gobiernos de izquierda que..] (186:196)/ (207:213).

10 27-06-09 Con la vara que midas, serás..., RDS.rtf - 48:5 [esta propuesta surgida desde a..] (11:11).

11 La adhesión del gobierno hondureño a la ALBA en 2008 "ubicaba a Honduras como un importante aliado en Centro América de los gobiernos de los movimientos sociales de América del Sur, denominados de izquierda y centro izquierda" (Irías, Saravia y Sosa, 2010: 9). De allí que no fuera casual el abierto apoyo de la derecha estadounidense a la ruptura constitucional" (Irías, Saravia y Sosa, 2010: 9). Méndez (2010) menciona también la primera visita oficial presidencial a Cuba en 46 años, la iniciativa de transformar la base militar estadounidense Palmerola en un aeropuerto internacional.

12 27-06-09 Con la vara que midas, serás..., RDS.rtf - 48:6 [Otras preguntas que fortalecen..] (11:11).

13 18-06-09 Paso la Bola, el gobierno de Mel y sus opositores.rtf - 29:9 [Creo que nos guste o no, es ju..] (149:155).

14 25-06-09 La derecha quiere un 11 de abril.rtf - 38:19 [“¿Qué es lo que los pobres re..] (133:140)/ (143:162).

15 25-06-09 Posición IV Urna.rtf - 41:5 [Por tener Buenos Gobiernos: Ho..] (60:60).
16 27-06-09 siete mensajes en este envío, RDS.rtf - 54:30 [En concreto en Honduras se nec..] (367:373).

17 26-06-09 seis mensajes en este envío, RDS.rtf - 45:6 [que en el país, se establezca ..] (32:38).

18 25-06-09 Documentos de Eduardo Barh.rtf - 36:47 [Sin embargo sabemos que todo e..] (103:103).

19 27-06-09 siete mensajes en este envío, RDS.rtf - 54:3 [organicémonos en círculos patr..] (22:27).

20 27-06-09 siete mensajes en este envío, RDS.rtf - 54:6 [Estamos Convocados En nuestro ..] (50:60).

21 26-06-09 siete mensajes en este envío, RDS.rtf - 46:19 [Condenamos esta acción golpist..] (36:36).

22 25-06-09 Documentos de Eduardo Barh.rtf - 36:30 [La propuesta que da paso a la ..] (68:68).

23 11-06-09 DESDE LA MOVILIZACION DE LA IV URNA. RDS.rtf - 17:7 [esta movilización local que co..] (49:50) y (162:176).

24 27-06-09 RE Posición IV Urna, RDS. rtf - 53:23 [Aspiramos a cambios sustancial..] (75:75).

25 27-06-09 RE Posición IV Urna, RDS. rtf - 53:22 [La Red de Comisiones Ciudadana..] (75:75).

26 27-06-09 RE Posición IV Urna, RDS. rtf - 53:17 [Este proyecto ya no es de Mel,...] (56:56).

27 25-06-09 Documentos de Eduardo Barh.rtf - 36:36 [la propuesta del Presidente ya..] (91:91)/ (92:92).

28 25-06-09 Documentos de Eduardo Barh.rtf - 36:26 [Empero, aún hay que responder ..] (59:59)/ (61:64). 
48 26-06-09 seis mensajes en este envío, RDS.rtf - 45:14 [hoy se abre a una nueva espera..] (73:78).

49 En el centro del pensamiento de Bloch se encuentra la forma en que el ser humano se concibe a sí mismo. Su conciencia no es solamente el producto de su ser, sino que, más aún, está dotada de un "excedente" que se expresa en las utopías.

50 26-06-09 seis mensajes en este envío, RDS.rtf - 45:12 [Da gusto y alegría ser parte d..] (67:69).

51 26-06-09 seis mensajes en este envío, RDS.rtf - 45:18 [Buscamos refundar una Honduras..] (87:88).

52 26-06-09 seis mensajes en este envío, RDS.rtf - 45:9 [Por el momento la soberanía de..] (52:54).

53 27-06-09 RE Posición IV Urna, RDS. rtf - 53:3 [Mañana, se inicia a escribir u..] $(13: 13)$.

54 26-06-09 seis mensajes en este envío, RDS.rtf - 45:8 [El pueblo está dispuesto a cim..] (46:50).

55 27-06-09 porque, RDS.rtf - 52:4 [no es el poder por el poder no..] (6:6).

56 18-06-09 Paso la Bola, el gobierno de Mel y sus opositores.rtf - 29:7 [Cada pueblo decide al final su..] (128:135).

57 La República Federal de Centro América surgió de la Asamblea Constituyente de las Provincias Unidas del Centro de América el 22 de noviembre de 1824. Estaba formada por cinco Estados: Guatemala, El Salvador, Honduras, Nicaragua y Costa Rica.

58 Francisco Morazán Quezada (Tegucigalpa, Honduras, 3 de octubre de 1792 - San José de Costa Rica, 15 de septiembre de 1842) fue un militar y político que gobernó a la República
Federal de Centro América durante el turbulento periodo de 1827 a 1842 . Reconocido como un gran pensador y visionario, intentó transformar a Centroamérica en una nación grande y progresista. Durante su gestión como mandatario de la República Federal, Morazán promulgó las reformas liberales, las cuales incluyeron: educación, libertad de prensa y de religión, entre otras. Además limitó el poder de la Iglesia católica con la abolición del diezmo de parte del gobierno y la separación del Estado y la Iglesia.

59 José Trinidad Cabañas Fiallos (Tegucigalpa, Honduras, 9 de junio de 1805 - Comayagua, Honduras, 8 de enero de 1871) fue un militar y político hondureño que fue presidente de la República de Honduras (1852-1855) y un defensor de las ideas liberales que apoyó la unión de Centroamérica. Es considerado prócer y una de las personas más honradas de la historia de Honduras. Durante su periodo de presidente sostuvo que: "No se trata de fundar la República de algunos, si no la República de todos". En su estatua erigida en el parque "La Mercedes", de Tegucigalpa, puede leerse: "Al Heroico Soldado de la unión centroamericana. Al guerrero modelo de constancia, de honradezy de valor".

60 Gustavo Adolfo Álvarez Martínez, (Tegucigalpa, 1938 - Tegucigalpa, 1989) fue un militar y político hondureño, jefe de Estado Mayor Conjunto de las Fuerzas Armadas de Honduras entre 1981-1984.

61 Gregorio Selser (Buenos Aires, 2 de julio de 1922 - Ciudad de México, 27 de agosto de 1991) fue un periodista e historiador argentino, reconocido por sus críticos como «un latinoamericanista comprometido con la libertad y la justicia». 


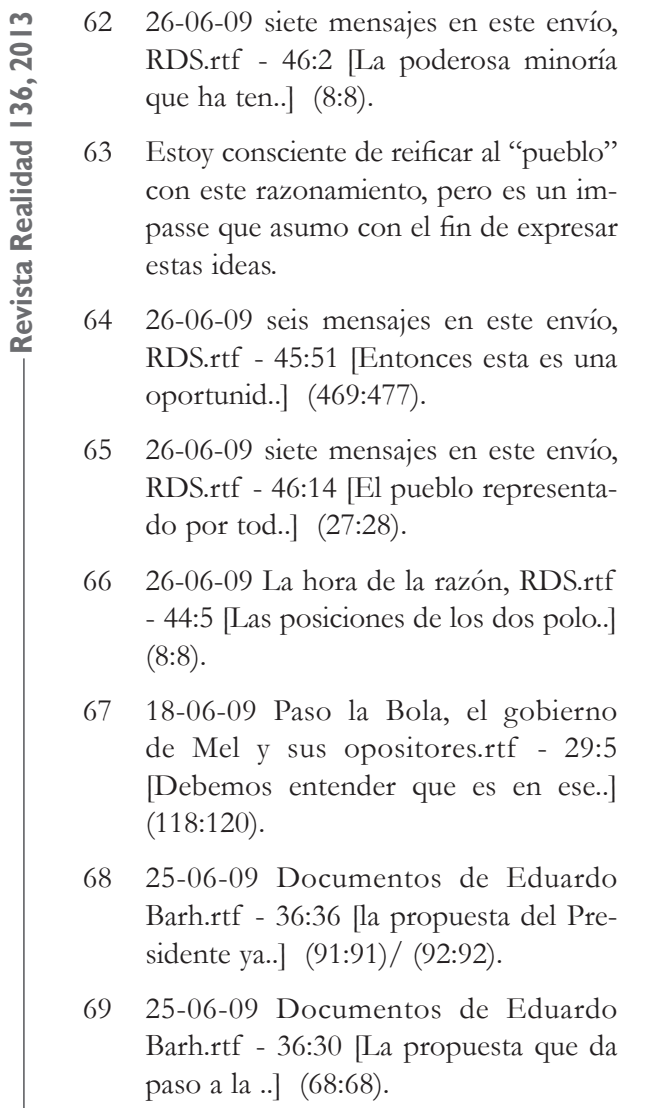

70 http://www.radiomundial.com.ve/ yvke/noticia.php?27930; http:// www.elnuevoempresario.com/noticia_10207_orden-de-muerte-paramanuel-zelaya.php; http://www.alternativabolivariana.org/modules.php?n ame $=$ News $\&$ file $=$ article $\&$ sid $=5240$, recuperados el 25/06/10.

71 25-06-09 La derecha quiere un 11 de abril.rtf - 38:1 [La derecha quiere un 11 de abr..] (5:14)/ (101:104).

72 26-06-09 siete mensajes en este envío, RDS.rtf - 46:12 [Rescataron las urnas de la con..] (24:24).

73 25-06-09 Dos mensajes en este envío. rtf - 37:2 [Viernes 26 de junio de 7:00 a...] (13:18).

74 19-06-09 Únete al Plantón De Este Viernes.rtf - 31:1 [1 PLANTON del VIERNES 19 DE JU..] (8:20).

75 26-06-09 seis mensajes en este envío, RDS.rtf - 45:7 [Y la minoría, representada por..] (40:42).

76 27-06-09 HONDURAS ES PRIMERO, RDS.rtf - 50:1 [una población aproximada de un..] (6:6). 